UNIVERSITY OF GRANADA

MASTER'S DEGREE IN GEOPHYSICS (GEOMET)

\title{
Mineral exploration of rock wastes from sulfide mining using airborne hyperspectral imaging
}

\author{
Da . Ana Bautista Gascueña
}

Supervisors:

Dra. M. Teresa Teixidó i Ullod

Dr. Moritz Kirsch

Academic year 2019/2020 
This work has been carried out in the framework of European Project: The Innovative, Non-invasive and Fully Acceptable Exploration Technologies (INFACT).

This project has received funding from the European Union's Horizon 2020 research and innovation programme under grant agreement $n^{\circ} 776487$.

The main INFACT-partners are:

* Coordinator: The Helmholtz-Zentrum Dresden-Rossendorf (HZDR)

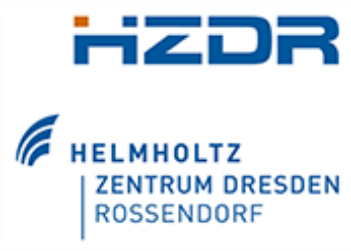

* Social dialogue \& environment:

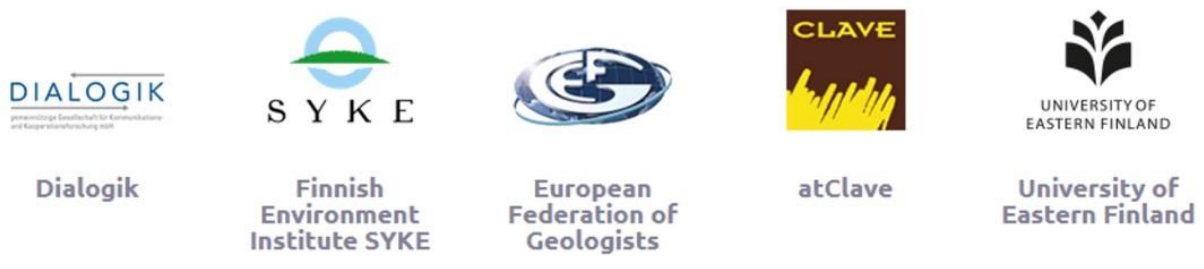

- Implementation \& business model

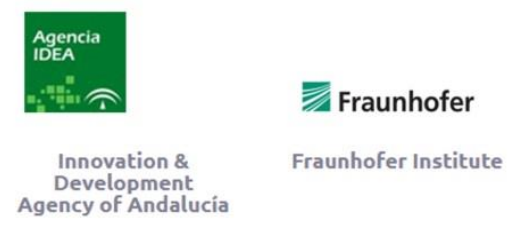

* Technical development \& exploration

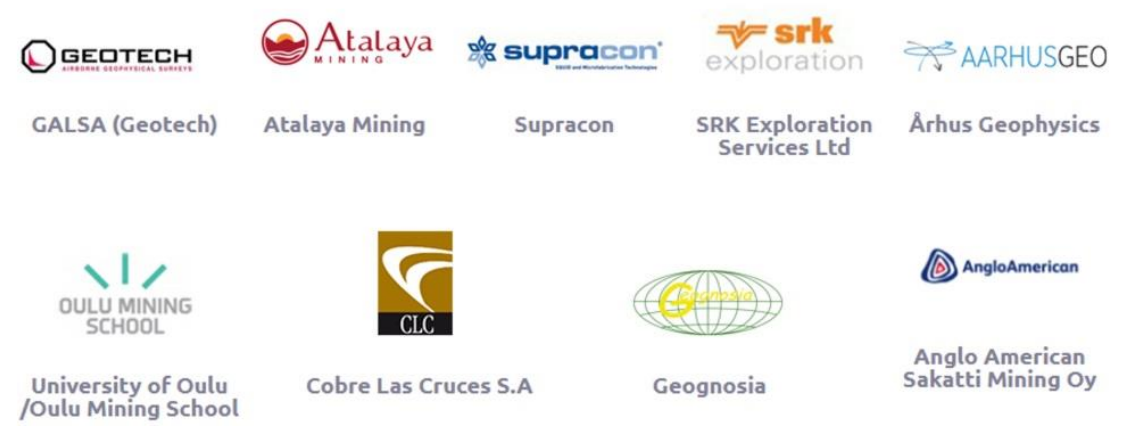




\begin{abstract}
Open-pit sulfide mining produces large quantities of waste rock that may contain materials of economic interest. The exposure of sulfides accumulation may also pose a hazard to the environment by causing phenomena such as acid mine drainage. This Master Thesis aims to map and provide a geological characterization of the rock wastes of Corta Atalaya open pit in Río Tinto, Spain. For this purpose, different hyperspectral imaging technologies that have already demonstrated their effectiveness in mineral detection such as airborne remote sensing in the VNIR and SWIR domain are used. This study is complemented with the incorporation of an innovative hyperspectral method, the airborne LWIR. Our approach makes use of a set of different spectral methods, and established image processing routines, such as band ratios, and minimum wavelength maps. Supervised classifications are also employed as a mean to extrapolate mapped rock types to larger unmapped areas, spectral angle maps, and to identify high abundances of endmember lithologies, spectral unmixing techniques. Furthermore, this study will lay the foundations and pave the way for possible future lines of research regarding the Corta Atalaya rock wastes.
\end{abstract}




\section{ACKNOWLEDGEMENTS}

This study has been done in collaboration with the Helmholtz Institute Freiberg for Resource Technology (HIF) and the Andalusian Institute of Geophysics from Granada University.

My most sincere gratitude for their contributions and support.
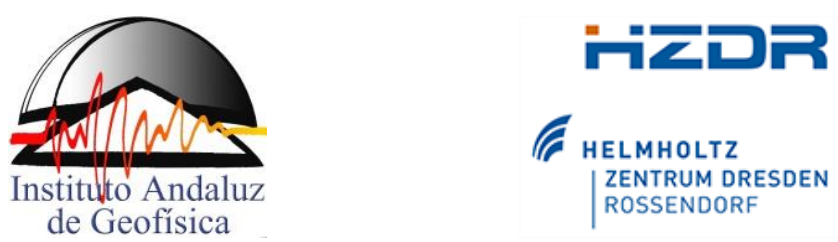

Gracias a mis dos tutores por el apoyo y el aprendizaje.

Y, sobre todo, por confiar en mí.

Gracias a mis padres por hacer que viva inmejorablemente.

Y, sobre todo, por confiar en mí. 


\section{TABLE OF CONTENTS}

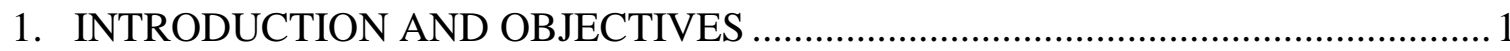

2. SPECTROSCOPY AND HYPERSPECTRAL IMAGING ....................................... 2

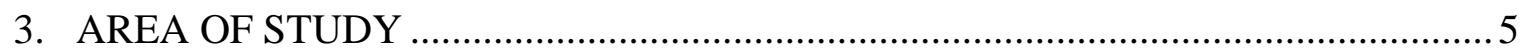

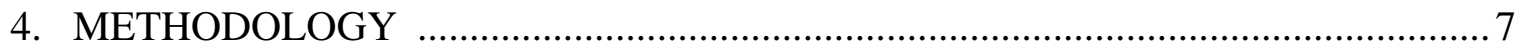

4.1 Data Inventory and Data Acquisiton........................................................... 7

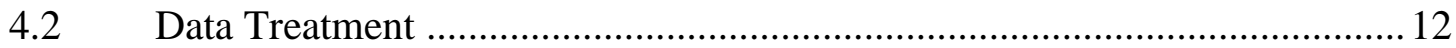

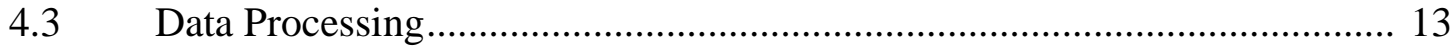

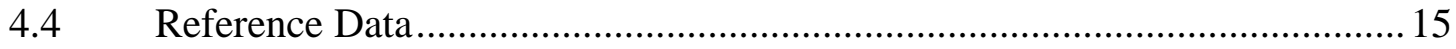

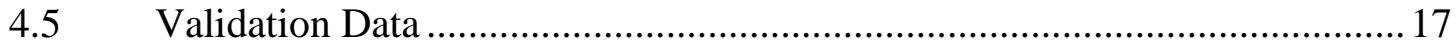

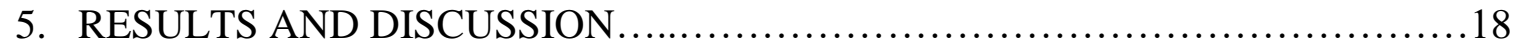

5.1 Test Sites Libraries and Classification Algorithms .................................... 18

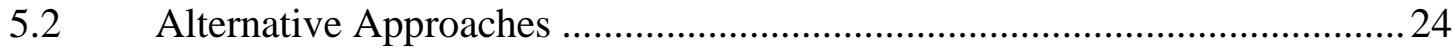

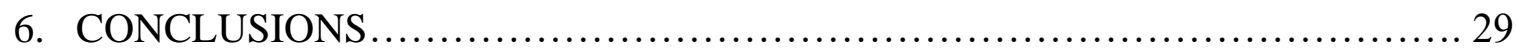

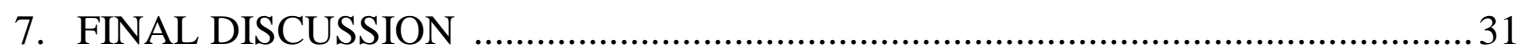

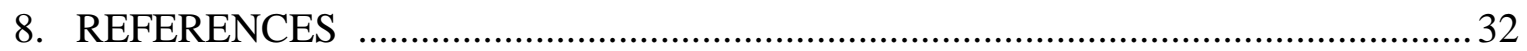

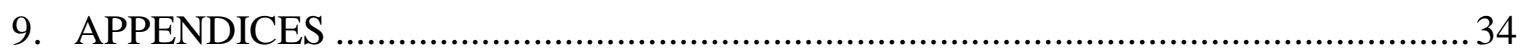

A1. Table 1. Representative XRD results for the test site lithologies............34

A2. Tecnichal specifications of cameras................................ 35

A3. Linear spectral unmixing results................................... 41

A4. Rock waste types spectral library $\quad$................................. 43 


\section{LIST OF ABBREVIATIONS}

\begin{tabular}{|l|l|}
\hline BR & Band Ratio \\
\hline FTIR & Fourier Transform infrared \\
\hline HS & Hyperspectral \\
\hline HSI & Hyperspectral image \\
\hline IPB & Iberian pyrite belt \\
\hline LSU & Linear spectral unmixing \\
\hline LWIR & Long wave infrared \\
\hline LSU & Linear Spectral Unmixing \\
\hline NDVI & Normalized Difference Vegetation Index \\
\hline MWL & Minimum wavelength \\
\hline PS & Purple Shales \\
\hline RGB & Red green blue \\
\hline ROI & Region of interest \\
\hline RT & Río Tinto \\
\hline SAM & Spectral angle map \\
\hline STK & Stockwork \\
\hline SWIR & Short wave infrared \\
\hline UAV & Unmanned aerial vehicle \\
\hline VNIR & Visible near infrared \\
\hline XRD & X-ray diffraction \\
\hline
\end{tabular}




\section{INTRODUCTION AND OBJECTIVES}

In the future, an enlarging demand for minerals is expected to supply the increasingly human needs. Circular economy thinking is an attractive topic nowadays and its implementation when it comes to mining may present a major opportunity in several aspects. As open-pit sulfide mining produces large amounts of rock waste that may contain materials of economic interest or may pose a hazard to the environment, knowledge and awareness of these is paramount. Mapping these rock wastes on the surface is important as an input to 3D resource modelling to better identify zones of mineralization for potential re-mining. Due to the development and improvement of mineral separation and processing techniques, a grand economic potential could be found in them. Moreover, a mineral characterization would also supply an accurate assessment of the environmental effects that this sulfide accumulation may suppose, such as the acid mine drainage (AMD). Ground-based surveying is the traditional method of mapping rock deposits, but is time-consuming, expensive, and potentially dangerous. In contrast, remote sensing, airborne hyperspectral imaging provides an innovative, non-invasive, safe, rapid, high-resolution, and accurate means to characterize mine waste deposits to assist in mapping and identifying zones of mineralization as well as estimating concentrations and quantities of profitable minerals. Airborne hyperspectral imaging in the VNIR and SWIR domain is an established method to map geological materials at the surface. On the contrary, Airborne LWIR is an innovative, untried method; its efficiency for the mapping of sulfidic rock wastes has yet to be evaluated.

\section{Objectives}

The overarching objective of this thesis is to assess the suitability/usefulness of airborne hyperspectral data in the visible to near-infrared, short-wave infrared, and long-wave infrared range for the mapping of sulfidic rock waste deposits. This assessment is based on an analysis of the mineralogical composition of the waste rock material using established image processing routines, such as band ratios, minimum wavelength maps, and spectral unmixing techniques. Supervised classifications are also employed as a means to extrapolate mapped rock types to larger unmapped areas and to identify high abundances of endmember lithologies. Based on the results of these analyses, the feasibility and efficiency of different workflows for the mineral exploration of waste rocks will be evaluated, taking into account different band ranges, training data sets, and algorithms. 


\section{SPECTROSCOPY AND HYPERSPECTRAL IMAGING}

\section{Principles of the method}

Spectroscopy is the study of the interaction between electromagnetic radiation (EMR) and matter. When electromagnetic radiation interacts with the earth's surface, various fractions or wavelengths of the energy are emitted, reflected, or scattered. Furthermore, any object whose temperature is greater than the absolute zero will emit a radiation whose amount changes as a function of wavelength (Manolakis et al., 2016). These two statements constitute the basis and physics foundations of the method on which this research is based, the behaviour of electromagnetic (EM) spectra along different wavelength ranges.

Maxwell's Laws describes that electromagnetic energy (EM) propagates in waves form formed by electric and magnetic fields. The different energy levels results in a range of different radiations that form the electromagnetic spectrum of radiation (Fig. 1). So that, the understanding and discrimination of the spectral characteristics, caused by the different physical and chemical properties of matter, can be used to help identify the constituents of minerals or molecular substances that make up the material (Lau, 2016).

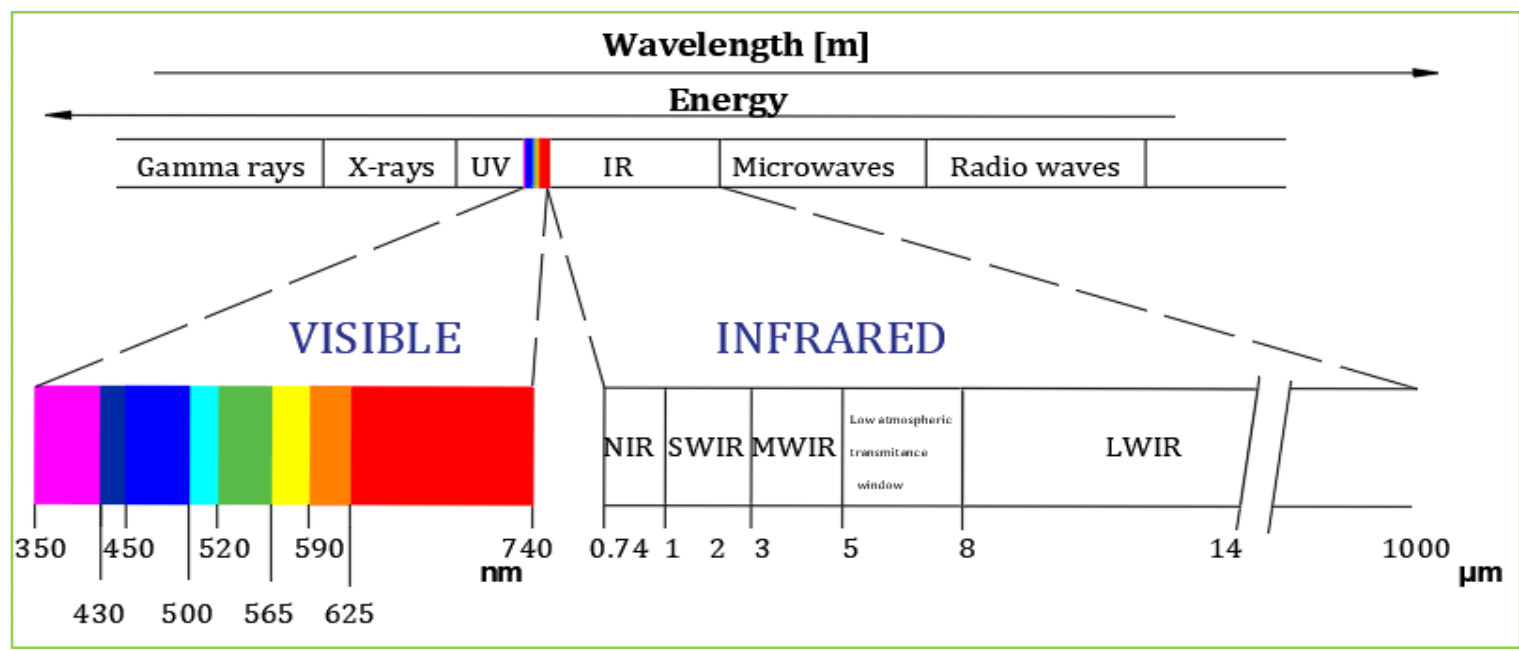

Fig. 1. Electromagnetic spectrum showing the visible and infrared wavelength intervals. The visible region has been expanded to show the wavelengths corresponding to the reflected colours seen by the human eye.

From an optical point of view, transparent materials are those that can be studied by analysing the light that passes through a sheet approximately $30-50 \mu \mathrm{m}$ thick. The rest of the materials are called absorbent media and, in general, correspond to conductive materials. However, there is a wide range of materials with intermediate properties; for example, coloured minerals absorb part of the radiation in the visible spectrum and allow others to pass through. Therefore, the concept of transparent or absorbent material depends, among other things, on the frequency. In any case, so-called absorbent materials cannot be studied by transmission and must therefore be analysed by reflection. 
When the light penetrates an absorbent medium, which can be considered to be divided into very thin sheets of identical infinitesimal thickness, the initial amplitude $\mathrm{E}_{0}$ decreases progressively as it passes through each of the sheets. The depth penetration (skin depth) can be defined as the thinckness that causes a decrease in the intensity equivalent to:

$$
e^{-1} \approx 1 / 3 \quad \text { Eq. } 1
$$

In a way the depth of penetration represents an assessment of the absorption capacity of a medium. For example, copper has a penetration depth of about $0.6 \mathrm{~nm}$ for ultraviolet $(\lambda=100$ $\mathrm{nm})$ and reaches $6 \mathrm{~nm}$ for infrared $(\lambda=10 \mathrm{~m})$, which suggests that the absorption coefficient has a significant dispersion along the electromagnetic spectrum.

On the other hand, the characteristic brightness of metals, and conductors in general, is due to the fact that light barely penetrates the medium and few electrons are ever "touched" by the radiation. Although each of them dissipates heat, the reality is that a very small fraction of the light energy is converted into heat. Much of the incident energy reappears as a reflected wave due to the re-emission caused by the free electrons in the conduction band. The explanation based on quantum theory is complex, however, an intuitive approach can be made by imagining that the material is a set of oscillators, some of which correspond to free electrons and others to electrons bound to atoms

Spectroscopy is the study of light as a function of the wavelength that has been emitted, reflected or scattered from a solid, liquid or gas.

As photons reach the surface of the material, some are reflected from the surface, some penetrate it, some are refracted, and some are absorbed by the material. Photons that are reflected from the surface or that are refracted are considered to have been dispersed. These photons can either be re-dispersed out of the material and captured by the detector or absorbed. Also, the material itself, just by being above absolute zero, is emitting photons that are also subject to the same physical laws of reflection, refraction and absorption as the incident photons (Clark, 1999).

The objective of spectroscopy is to obtain and interpret the absorption, reflection and emission properties of a target material. Unlike transmitted light spectroscopy, which is commonly used by chemists in laboratory environments, reflectivity spectroscopy supports a number of different scenarios. In remote sensing, spectrometers have been installed on satellites and aircraft and have been used in various scientific applications such as the control of the tree canopy, observations of the ecosystem and urban development, and geological, environmental and planning research.

\section{Hyperspectral Imaging}

Within geology, mineral identification is possible as most minerals have unique characteristic spectral signatures or spectra. The wavelength windows used in reflectivity spectroscopy are approximately standardised according to Table 1. The specific ranges of interest will be the visible to near-infrared (VNIR) extending from 400 to $1000 \mathrm{~nm}$, the shortwave infrared range (SWIR), from 1000 to $2400 \mathrm{~nm}$ and the long wave infrared (LWIR), from 7000 to $14000 \mathrm{~nm}$. 
Table 1. Wavelet-time windows used in standard spectoscopy

\begin{tabular}{|l|c|c|c|}
\hline Name & Acronym & $\lambda$ initial [nm] & $\lambda$ final [nm] \\
\hline Ultraviolet & UV & 1 & 400 \\
\hline Visible & VIS & 400 & 700 \\
\hline Visible to near infrared & VNIR & 700 & 1000 \\
\hline Shortwave infrared & SWIR & 1000 & 2500 \\
\hline Medium infrared & MIR & 2500 & 8000 \\
\hline Long Wave infrared & LWIR & 8000 & 140000 \\
\hline
\end{tabular}

Reflectance spectroscopy mainly studies the VNIR and SWIR regions of the EM spectrum. The radiation emitted by the Sun is modified by the earth's atmosphere and surface, therefore reflectivity will be measured. In the LWIR domain, the radiation emitted by the Sun interaction and self-emission of materials in the scene due to their temperature will be used (Fig. 2). All these electromagnetic interactions can be detected and measured by spectrometers producing spectral images.

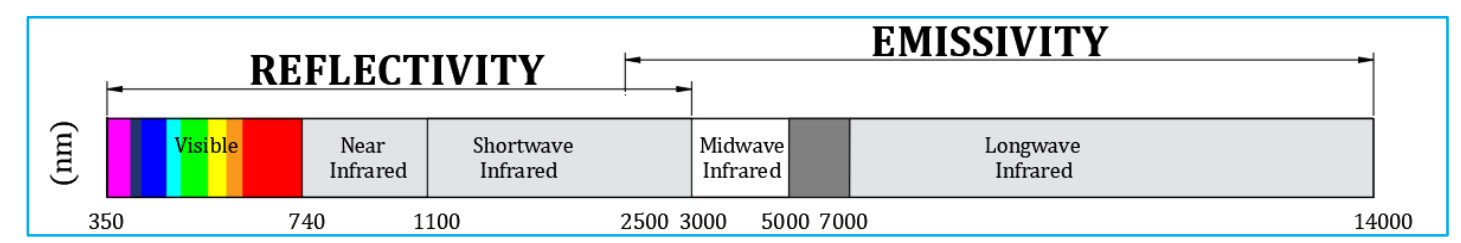

Fig. 2. Scheme indicating which type of infrared energy will be used in this study depending on the specific range concerned.

Hyperspectral imaging (HSI) spectroscopy is used to spatially map and spectrally identify matter based on its specific chemical properties (Clark, 1999). HSI sensors used to acquire the data are mainly composed of an imaging system, a scanning mechanism, and a spectrometer (Manolakis et al., 2016). For each pixel of the image, many bands of spectral data are acquired giving a data cube (3D) as an output: spatial data in 2D and spectral data along the third axis. In contrast to multispectral imaging (MSI) systems which contain only a few broad spectral channels (Clark, 1999), HSI are much more sophisticated and accurate in terms of spectral resolution and mineral identification since they contain a continuous spectrum over a certain wavelength range for each pixel (Goetz, 2009) (Fig. 3.) 


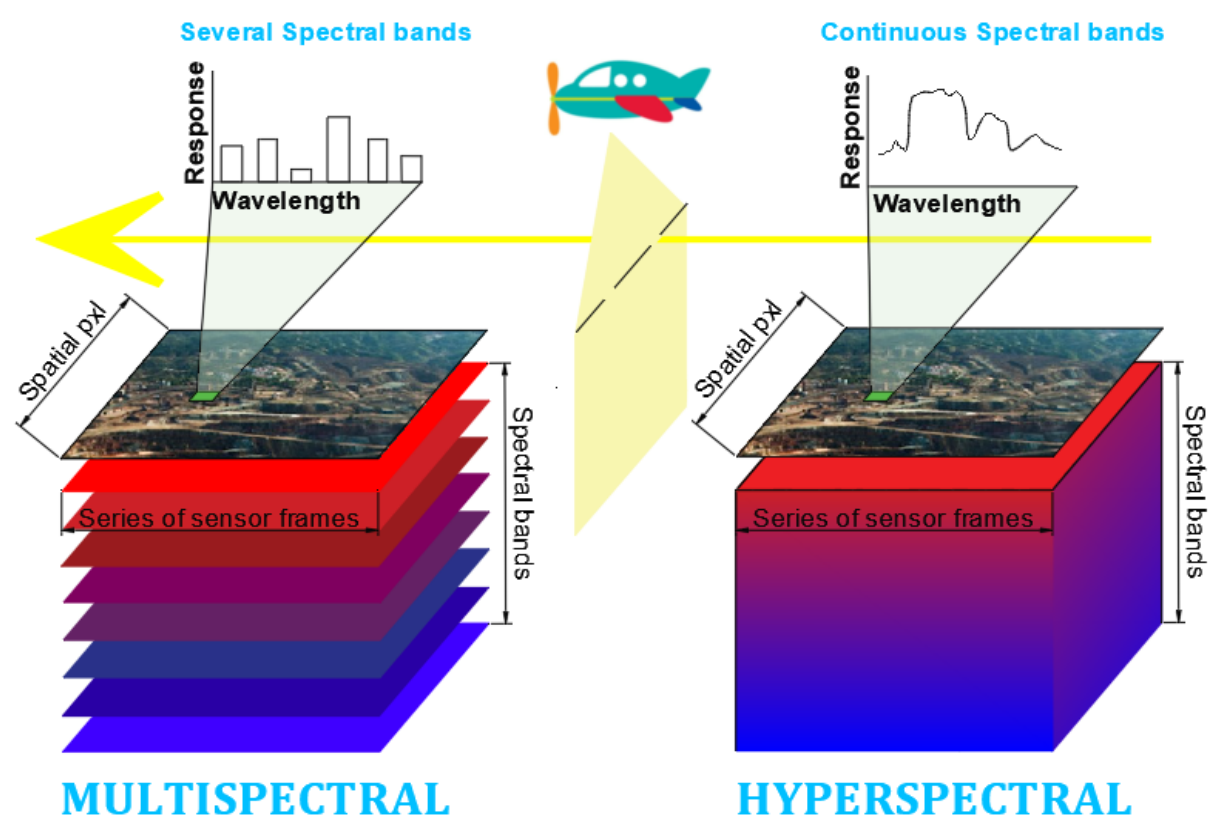

Fig. 3. Conceptual figure to explain the difference between multispectral and hyperspectral Imaging.

\section{AREA OF STUDY}

The Iberian Pyrite Belt (IPB) is part of the South Portuguese-Spanish Zone (Fig. 4.) of the Hercynian Iberian Massif (Julivert et al. 1974). It is located in the SW part of the Iberian Peninsula hosting the largest concentration of polymetallic massive sulphides on Earth (Inverno et al., 2015). This metallogenic province which has an extension of $250 \times 20-70 \mathrm{~km}$, presents three different types of sulfide mineralization: Massive sulfide, banded sulfides and stockwork. It is estimated that its ore reserves, distributed in eight supergiant deposits, exceed $2500 \mathrm{Mt}$ (Sa, 1999). One of the main and best-known deposits of the IPB is Rio Tinto (RT). Its lengthy history and mining tradition that dates back to the Tartessian period (XXX century $\mathrm{BC})$, thus becoming a hallmark that has determined the economy, culture, and development of the area (Ortiz Mateo, 2004).

IPB has suffered a Variscan deformation occurred during the early Carboniferous (Upper Viseense - Upper Moscoviense). Due to intense hydrothermal activity, these fractures served as feeding structures for the stockwork formation. RT is formed by paleozoic materials which can be mainly divided into three groups: (i) the Phyllite-Quartzite Group (PQ), (ii) the Volcano- Sedimentary Complex (VSC) and (iii) the Culm Group (Olias Alvarez et al., 2008). The two main structural units at Rio Tinto zone are (i) the upper one composed of materials from the Culm Group which presents a breakaway at its base with a black phylonite of $20 \mathrm{~m}$ in strength (Gonz, 2006). Under this phylonite there is a pile of interlocking tectonic klippes. Each of these has inside thrust faults and minor folds dipping to the south, with a thickness that can reach $2 \mathrm{~km}$. This Culm group is, therefore, the host of the sulfides that emerge in this part of the Iberian Pyrite Belt (González et al., 2002). 

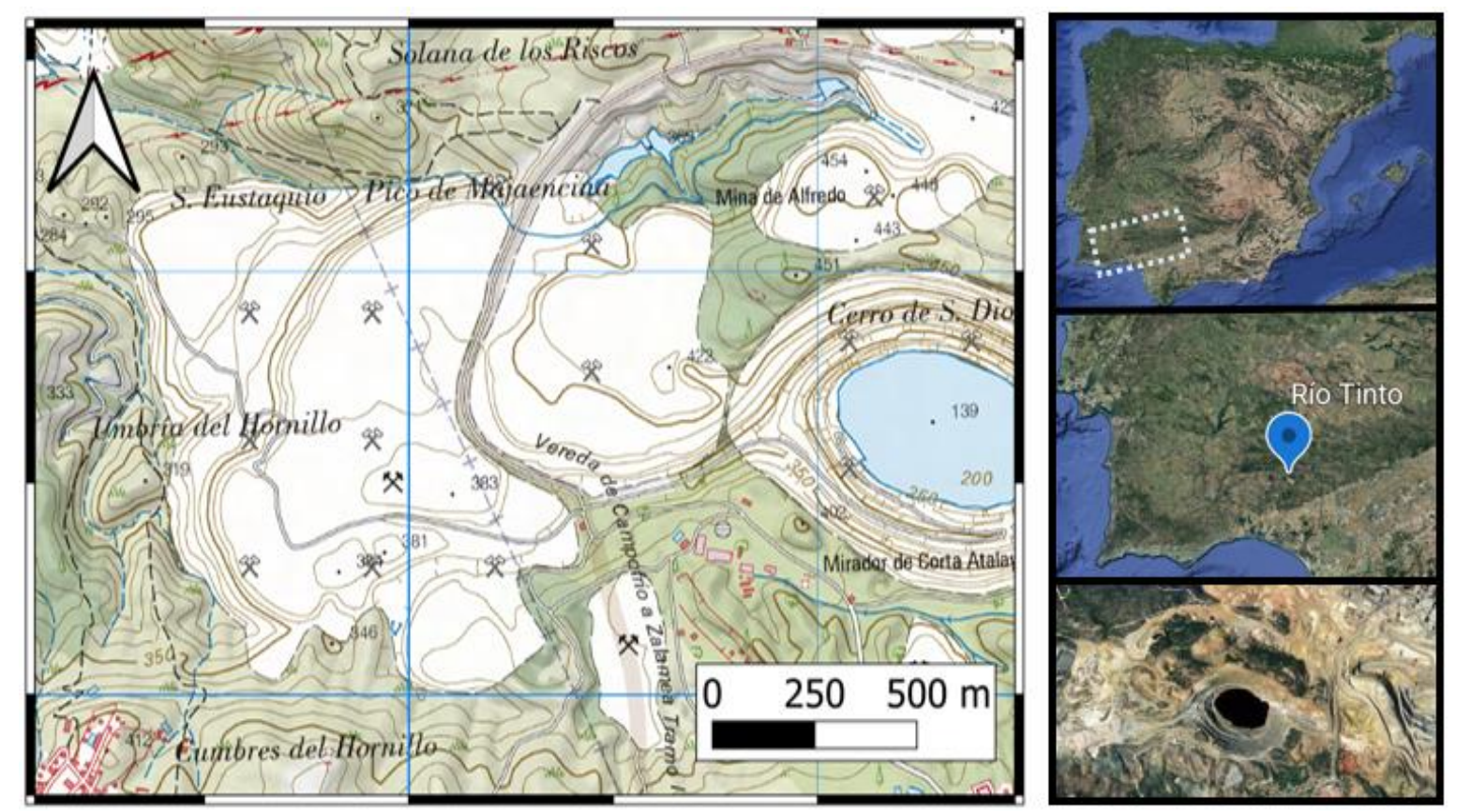

Fig. 4. Topographic map of the target area, the rock waste of Corta Atalaya (IGN). In the right part of the image composition and from top to bottom, location maps of the Iberian Pyrite Belt, Río Tinto mining district, and an aerial view of the target area. (Google Earth).

RT today still holds 197 megatons of copper, besides, the three characteristic IPB sulfide mineralizations are found, predominating minerals such as pyrite (FeS2) and chalcopyrite $(\mathrm{CuFeS} 2)$, and to a lesser extent, sphalerite or blende $(\mathrm{ZnS})$ and galena $(\mathrm{PbS})$.

Corta Atalaya was one of the most ambitious projects of modern intensive mining of the 20th century. It was born as a result of the collapse of the previous underground mine, giving way to an open-pit excavation with a size of $1200 \times 900 \mathrm{~m}$ and a maximum depth of $365 \mathrm{~m}$. It was operational from 1907 to 1992 when it was permanently closed, by then having already produced more than 2000 tons of profitable minerals. The rock wastes resulting from the mining process of Corta Atalaya lay in the immediate vicinity of the open pit and will constitute the area on which this study will be focused. 


\section{METHODOLOGY}

This chapter is intended to give an overview of the workflow followed and explain the techniques, algorithms, and parameters applied to the raw data. The framework and main steps are shown in the chart on Fig. 5.

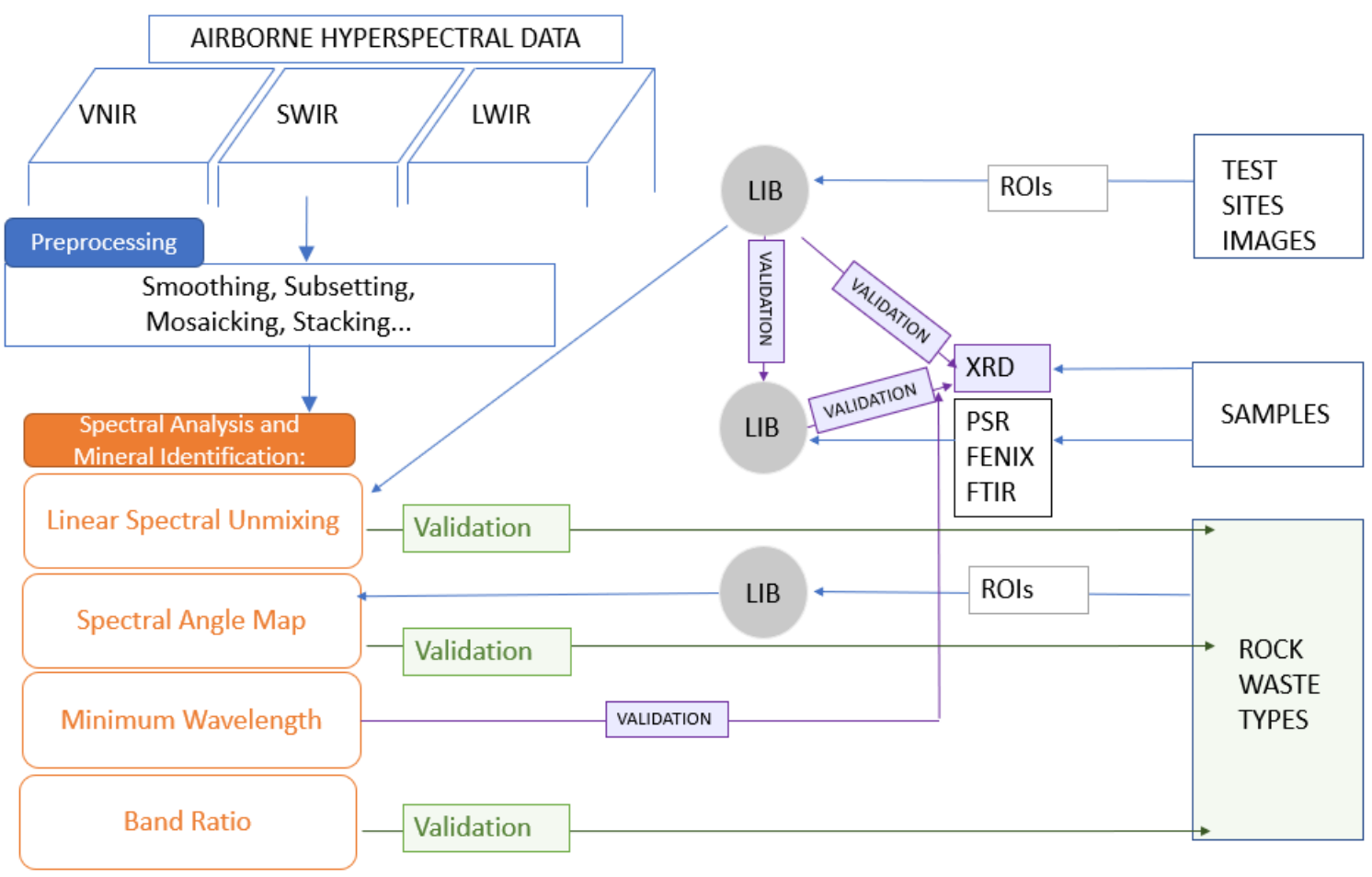

Fig. 5. Implemented processing chain over the Hyperspectral Images for mapping. VNIR=Visible to near infrared. SWIR=Short wave infrared. LWIR=Long wave infrared. ROIs=Regions of interest. LIB=Spectral library. XRD=X-ray diffraction. PSR=Portable spectroradiometer. FTIR= Fourier Transform infrared.

After preprocessing and conditioning the airborne HSI, a set of procedures are applied on the images for mineral characterization and mapping. For doing so, several algorithms are employed using conventional processing methods based on the spectral behaviour (band ratios and minimum wavelength maps), and some other utilizing reference data as an input (spectral angle map and linear spectral unmixing). Both reference data and resulting mineral maps are validated and supported with ground or other types of measures (XRD analysis and spectral from different sources).

\subsection{DATA INVENTORY AND ACQUISITION}

The data acquisition for this research was done through two different routes. The firts one was an aerial campaign in July/August 2020 covered the whole area of interest, and a total of three HSI datasets corresponding to the VNIR, SWIR, and LWIR domains were obtained. The technical details of these flights, specifications of the sensors used, and a brief overview of the preprocessing and corrections to be applied to the raw images are described. 
In parallel, a ground sampling and validation terrestrial campaign were carried out, the data procurement for this stage can be separated into three complementary parts: (1) Different hand samples for visual identification belonging to the seven most important lithologies present in Rio Tinto were collected. These lithologies, which will eventually form one of the reference data sets serving as input for the subsequently supervised classifications are as follows: gossan, massive sulfide, stockwork, argillic alteration, purple shales, culm shales, and chloritic volcanic rocks. (2) Finally, in situ measurements of the characteristic spectrum of the samples in question were made and (3) a set of those were taken for both mineralogical and further spectral laboratory analysis and characterization. As well as for the airborne campaign, all methods and sensors employed for each characterization will be described.

\section{Airborne HSI}
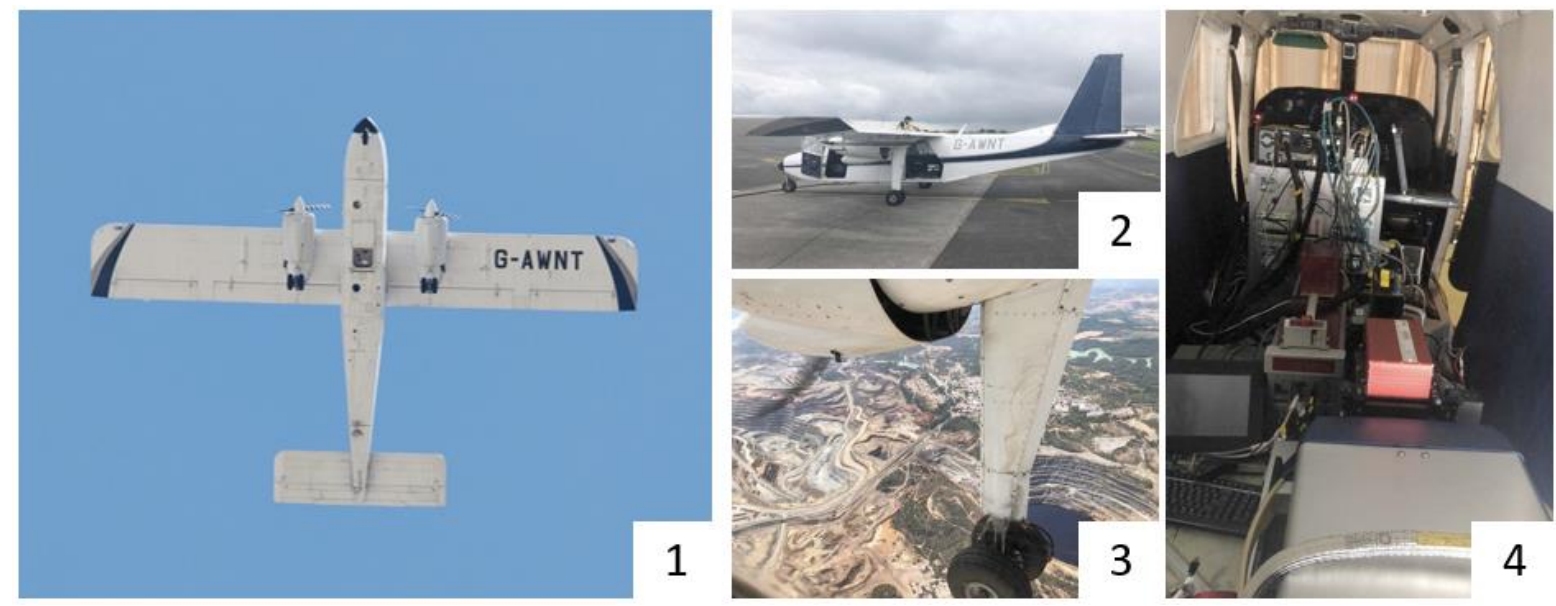

Fig. 6. Images from the INFACT airborne hyperspectral campaign in July/August 2020, showing a BN 2 fixedwing aircraft and installed hyperspectral instruments.

In order to obtain the Hyperspectral image data of the Río Tinto mining district, several flights were made using a BN 2 fixed-wing aircraft based in Seville (Fig. 6). These flights were carrying hyperspectral cameras which collected data in three-dimensional data-cubes composed of a set of pixels, containing the measurement corresponding to a specific wavelength range. The weather conditions of the field campaign days were hot and sunny as it was summer.

\section{- VNIR-SWIR}

The acquisition of the airborne hyperspectral images both in the VNIR and in the SWIR domain were performed simultaneously as the aircraft was carrying both cameras. A total of 36 lines (labeled from 08 to 44) were flown at a height of 900 meters following an east-west direction with a $230 \mathrm{~m}$ line spacing, forming a mosaic that covers the entire target area. Additionally, single line flights were conducted over a test site (see below) at different heights $(600,900$, and 1200 meters). All the flight lines are $10 \mathrm{~km}$ long and 600 metres wide and overlap each other for better data coverage. In the VNIR domain the Hyspex Classic VNIR 1800 sensor (Fig. 9) was used, recording up to 160 bands from $415.4 \mathrm{~nm}$ to $992 \mathrm{~nm}$, 
(3.7 $\mathrm{nm}$ bandwidth), and resulting in an image with a pixel spatial resolution of 0.6 meters. At the same time, in the SWIR domain, a total of 256 bands between $968.4 \mathrm{~nm}$ and $2498 \mathrm{~nm}(6$ nm bandwidth) were recorded using a HySpex SWIR 384 sensor (Fig. 9), giving a spatial pixel resolution of $1.25 \mathrm{~m}$. The data processing both for VNIR and SWIR HSI can be divided into three steps, following a consecutive correction process. In the first place, the raw data was converted to imageries in radiance units. Later, a georectification correction was performed, which consisted of marking ground control points on hyperspectral images using a reference map and creating a boresight file and, through an iterative process, obtaining fullband georectified imagery. Finally, the atmospheric distortions were removed by using a flat terrain model, a scan angle file, and a tabulated atmospheric factor corresponding to a rural area and a water column of $0.4 / \mathrm{cm}^{2}$. As a final product we obtain several HSI datasets in which the reflectance of each pixel is measured along a wide wavelength range expressed in micrometers.

\section{* LWIR}

In this case, the acquisition of the HSI dataset in the LWIR domain was acquired simultaneously with the LIDAR, using a thermal lightweight and compact hyperspectral camera. In the same way as for the VNIR-SWIR, single line flights were conducted over a test site at different heights $(600,900$, and 1200 meters). Hyperspectral data from both the main flight and the 600-meter test site flight is used in this work. The HSI instrument used was the Telops Hypercam L-W (Fig. 9), a Fast Fourier Transform (FFT) spectrometer that records 126 bands per pixel covering a spectral range of 7829.7-11468 nm with a bandwidth of $30.5 \mathrm{~nm}$ wavelength. The image preprocessing for the LWIR case was very similar to that for the VNIR and SWIR ones. In the same way as in the previous section, the raw data were converted to images in radiance units, a georectification was performed and finally, an atmospheric correction was performed separating emissivity from temperature. This time we obtain a single dataset that records emissivity instead of reflectance and whose wavelength range is expressed in wavelength number units.

\section{Ground Sampling and Lab Validation}

In the course of the 4-day field campaign, while the flights described above were conducted, different types of ground truthing data were collected. The first step was designing a reference/test site area (Fig. 7.) with the most important lithologies of Río Tinto listed above. For this purpose, samples of each lithology were piled up in a flat area, forming rectangles of varying extensions, ranging from 15.5 square meters for the gossan, the smallest reference site, to 27 square meters for the argillic alteration. No area was designed for the chloritic volcanics as it is the characteristic material of the entire surface layer, being present everywhere. All of them are large enough to be visually distinguishable in the airborne HSI obtained.

For a better characterization of the lithologies that conform the reference sites, samples were collected, and a mineralogical analysis was conducted by powder X-Ray diffraction (XRD) (Appendix A1). Moreover, manual spectral points measurements of characteristic spectra of test sites lithologies were acquired in situ with handheld spectrometers and later under laboratory conditions. All samples and spectra measures collected were assembled 
for the purpose of using spectral features for the remote detection and mapping of these and similar materials. The Helmholtz Institute Freiberg for Resource Technology provided the laboratories for these analytical studies and spectral measurements. The Helmholtz Institute Freiberg for Resource Technology provided the laboratories for these analytical studies and spectral measurements.

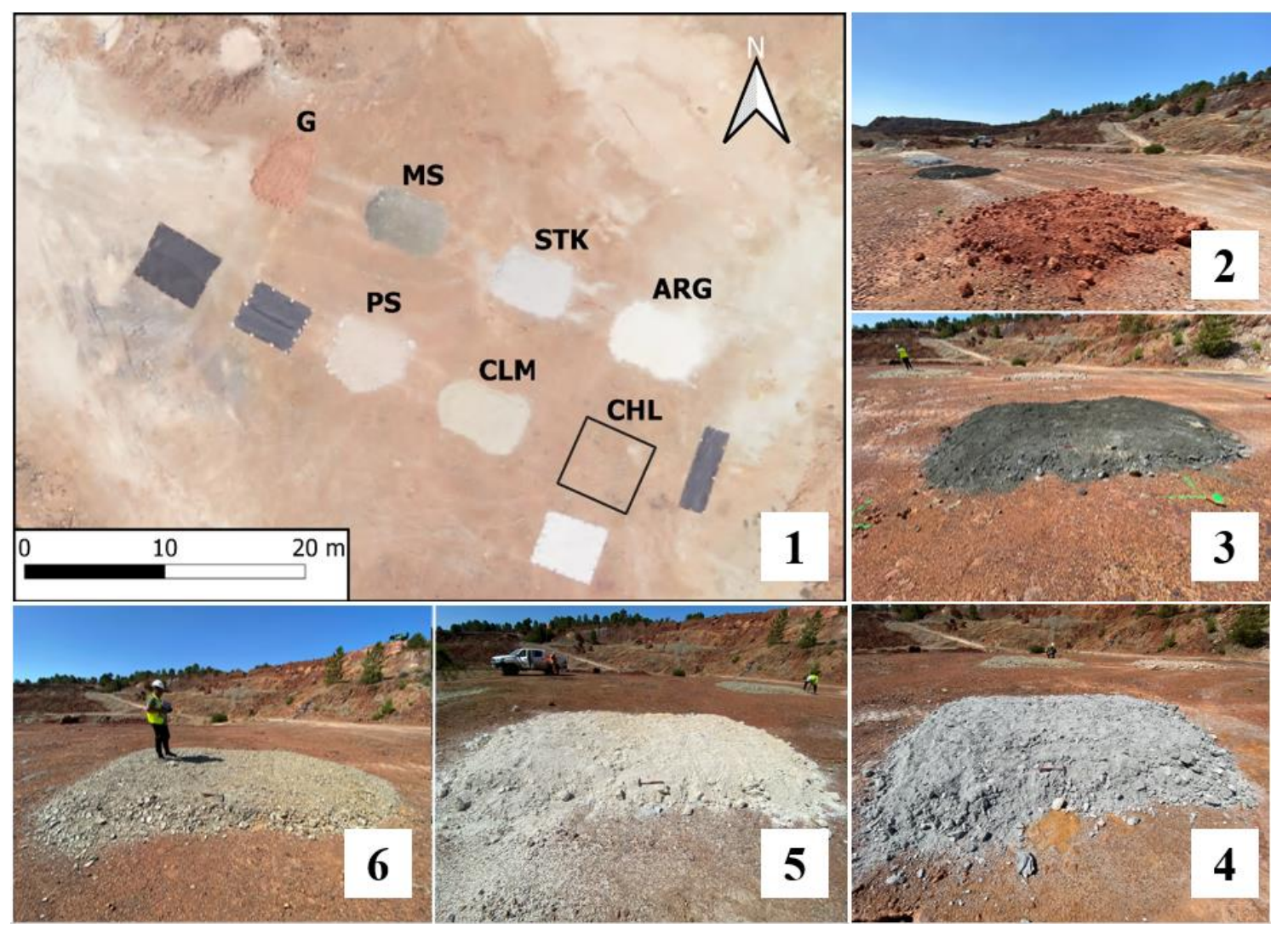

Fig. 7. Reference/test site for airborne hyperspectral mineral mapping with endmember lithologies set up in the survey area. Image 1 shows the aerial view of the test sites area. From number 2 to 6 real size images of the test sites (gossan, massive sulfide, stockwork, argillic alteration and Culm shales).

\section{- Lab Spectra}

Laboratory spectra was acquired using a drill core scanner equipped with an Aisa Fenix HS camera (Fig. 9). This sensor is composed of two different detectors CMOS and Stirling cooled MCT which cover the VNIR (380-970 nm) and SWIR (970-2500 nm) ranges of the EM spectrum respectively and each provide a spectral resolution (Full Width at Half Maximum-FWHM) of $3.5 \mathrm{~nm}$ ands $12 \mathrm{~nm}$. The fully automatic workstation makes use of a retractable table to pass the samples under the field of view of the camera which remains fixed at the top.

\section{*ield Spectra}

A portable Spectral Evolution PSR 3500 (Fig. 9.) spectroradiometer was used to acquire in situ spectra measurements providing fast quantitative assessment. This sensor records up to 1024 bands between 350 and $2500 \mathrm{~nm}$ at a spectral resolution of $3.5 \mathrm{~nm}$ (1-5 nm bandwidth between 350 and $1000 \mathrm{~nm})$ and $7 \mathrm{~nm}(2-5 \mathrm{~nm}$ between 970 and $2500 \mathrm{~nm})$. In order to subtract the instrument spectral response, a calibration was done before and during the acquisition with a material that has about $99 \%$ reflectance over the entire spectral range. Exceptionally, 
for dark samples with a noisy spectrum, a material with less reflection was used for calibrating. These hand-held spectral measurements were taken placing the sensor tip 1 meter above the samples surface (Fig. 8.) and each spectral record consists of 10 individual measurements taken consecutively and averaged.
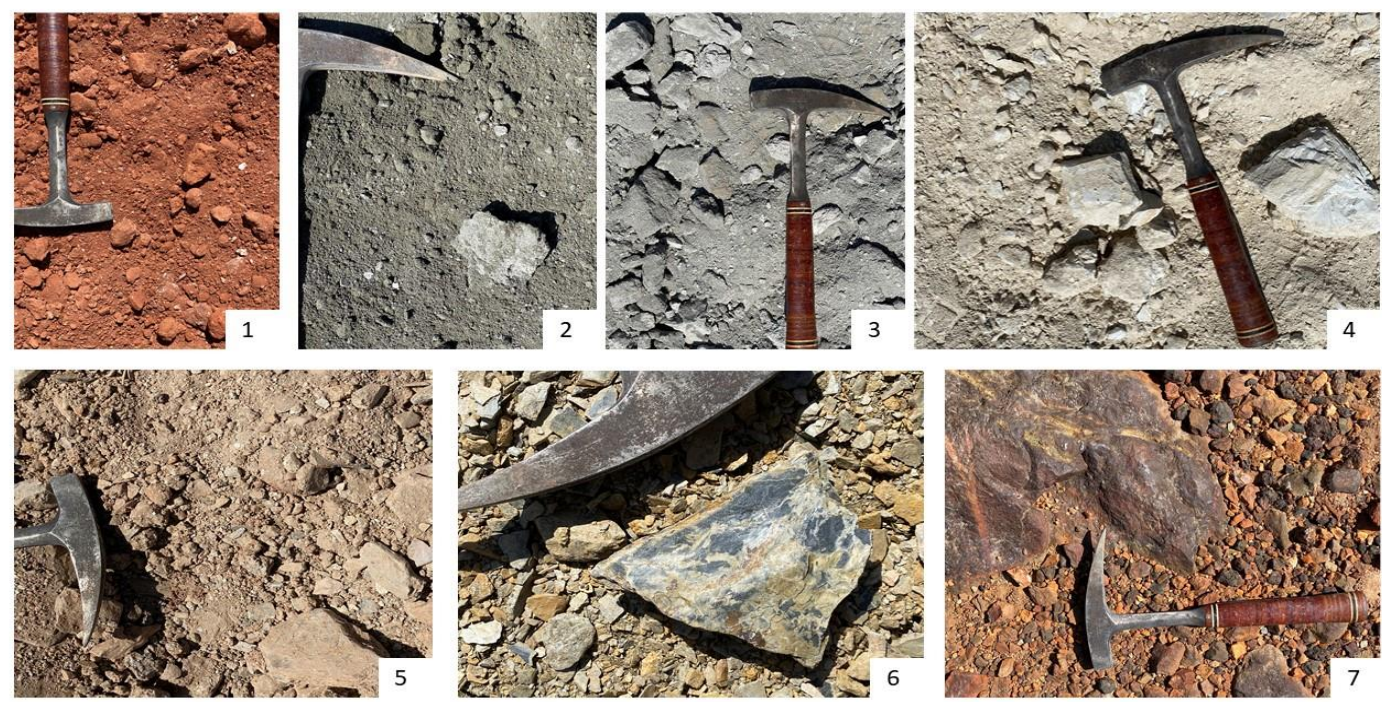

Fig. 8. Detailed view of the lithologies and rock types that constitute the reference sites from which field measurements were acquired and hand samples were collected for further laboratory analysis. $1=$ gossan, $2=$ massive sulfide, $3=$ stockwork, $4=$ purple shales, $5=$ culm shales, $\mathrm{CHL}=$ chloritic volcanics .

Field measurements in the MWIR to LWIR were taken using an Agilent 4300 Fourier Transform Infrared spectrometer (Fig. 9.). This sensor was set to a spectral resolution of 8 $\mathrm{cm}^{\wedge}-1$. The radiance values obtained were converted automatically to reflectance using a precalibrated SpectraGold target with $>95 \%$ reflectance. For each scan, the arithmetic mean of 32 consecutive individual measurements was calculated.

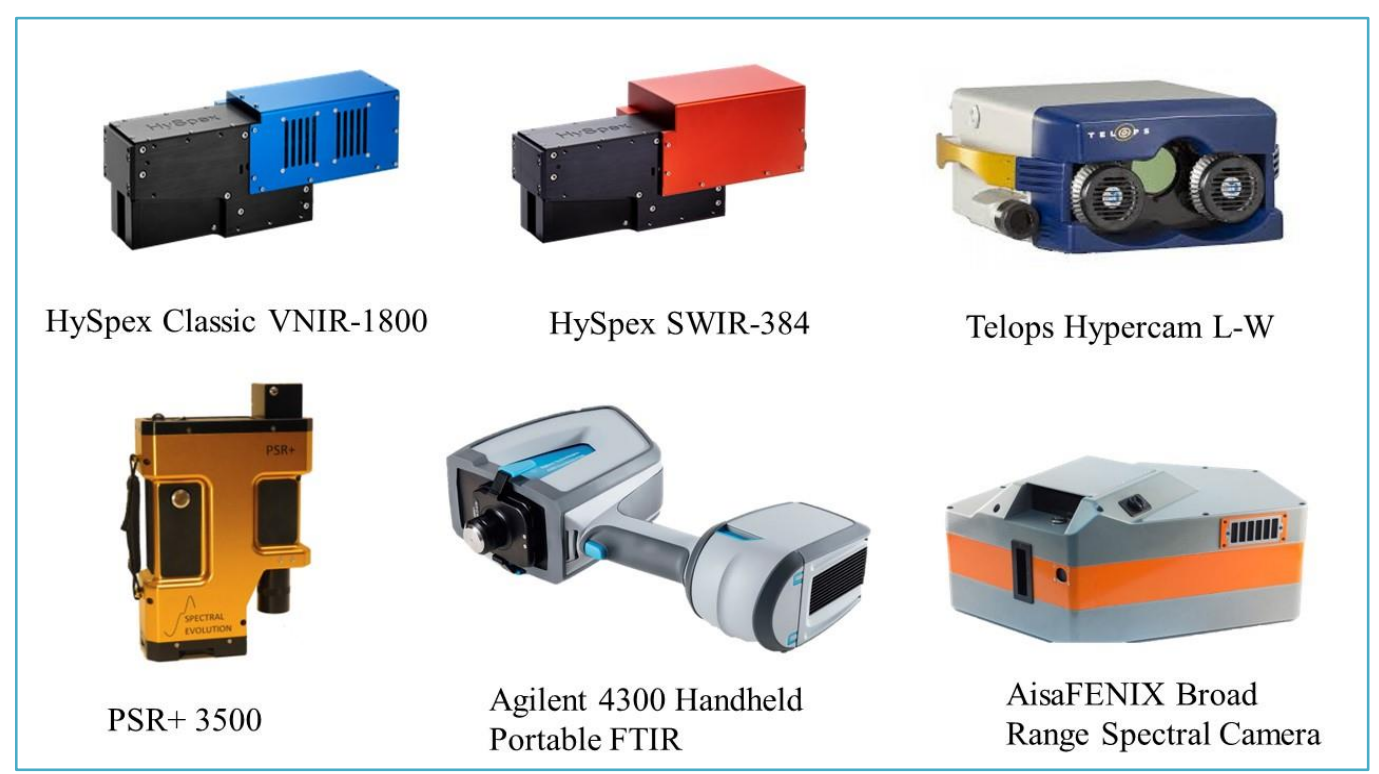

Fig. 9. Hyperspectral sensors used for data acquisition. At the top of the image and from left to right are the HySpex VNIR, HySpex SWIR and Telops Hypercam L-W, used in the airborne data acquisition. At the bottom are the sensors and cameras used for the ground sampling and validation from left to right are: PSR +3500 and Agilent 4300 FTIR for field spectra and AisaFenix for lab spectra from hand samples. 


\subsection{DATA TREATMENT}

The resolution and spectral range of the airborne HSI acquired enable the identification and mapping of minerals. However, working with the raw data cubes can be tedious due to their size, and a little spectral signal conditioning is also convenient. This section briefly outlines the treatment process to be followed for these.

\section{Smoothing}

As the raw data cubes are very noisy and, in some cases, it is quite difficult to determine the general spectral trend and absorptions by means of visual evaluation, smoothing was performed using the THOR Workflow Tool Spectral Smoothing in ENVI. This function uses the Savitzky-Golay smoothing filter to soften the noise of the signal. The parameters that configure this tool are the filter width, the derivative order (set to zero by default), and the degree of the smoothing polynomial. Larger filter width values produce a softer outcome at the expense of flattening the sharp peaks and valleys. Typical values for the polynomial smoothing degree are 2 to 4 and must be lower than the width of the filter. For the hyperspectral images corresponding to the VNIR and SWIR ranges, the filter bandwidth used was five and the degree of the polynomial, two. On the contrary, for the hyperspectral image in the LWIR domain, a third-grade polynomial filter and bandwidth 9 was applied.

\section{Mosaicking}

The flight bearing the LWIR domain HS camera covered the entire area of interest in a single flight line. However, in the case of the VNIR and SWIR, as the field of view of the corresponding HS cameras is lower than the Telops camera, several flight lines had to be made to cover the Rio Tinto areat. These flight lines had to be merged to obtain the whole geographical area of the rock waste, for this purpose the ENVI georeferenced-based Mosaicking Tool was implemented. The software also provides useful tools for common requirements such as feathering the edges of overlapping areas and image border transparency. The flight lines that compose the target area are the following 25, 26, 28, 30, and 32. However, for the VNIR after a slight visual examination, it was decided that lines 23, 28 , and 32 would be dispensed with as the reflectance values ( $\mathrm{Y}$-axis) were overestimated for all pixels, thus giving not so much erroneous data but misleading inconsistent with the rest of the images and highly susceptible to give rise to errors in future processing.

\section{Stacking}

The layer stacking tool in ENVI is used to concatenate hyperspectral images with different frequency or wavelength ranges. Establishing the order of the data cubes images logically and setting a pixel size for the resulting image is primordial. The image comprising the smallest wavelength range will be placed above and, in order to lose as little information as possible, the pixel size will be the one belonging to the image with the highest spatial resolution.

\section{Vegetation Removal NDVI}

Existing vegetation can yield erroneous values in mineral classifications in HSI. Pixels containing vegetation, show a characteristic spectral signature in the Red and Near IR ranges a band ratio (the inner working of this algorithm will be discussed further in the 4.3 section), automatically determines which pixels correspond to vegetation. The vegetation mask will be extrapolated to the rest of the HSI datacubes removing the corresponding pixels. 


\subsection{DATA PROCESSING}

This chapter comprises a detailed explanation of the largely automatized approaches, adapted algorithms, and tools used to obtain mineral estimates and classifications.

First, refined techniques and procedures are implemented. These are the classification algorithms, which can be supervised or unsupervised. Supervised ones use class-specific probes provided by training samples and may well trigger the classification maps more accurately than the others (Ghamisi et al., 2017). The methods used will be Linear Spectral Unmixing (LSU) and Spectral Angle Map (SAM). These two classifications are applied through the entire wavelength range of the spectral dataset in question. LSU estimates abundances while SAM assigns each pixel to the most predominant lithology present.

Later in this section, two search tools will be applied. These are the calculation of band ratios and the minimum wavelength mapper. These are focused on the study of specific parts of the wavelength range.

\section{$S A M$}

The spectral Angle Mapper (SAM) is a supervised matching algorithm that permits rapid mapping of the similarity of image spectra to a reference spectrum (Boardman 1993). The spectra of each pixel are expressed as vectors in an n-dimensional coordinate system with an $\mathrm{N}$ equal number of available bands (Kruse et al., 1993). SAM represses the influence of shading effects to accentuate the target characteristics (De Carvalho et al., 2000). The similarity between two spectra is determined according to the angle formed by the characteristic vector of these. After comparing, each pixel is then assigned to the class that displays the smallest angle (Fig. 10.). The classification image given as output shows the best match to the endmembers for each pixel and several rule images, one for each endmember, are produced showing the spectral angle value for each individual pixel. For a more accurate classification, the threshold range for the similarity analysis, relied on very small angles (around $0.1 \mathrm{rad}$ ).

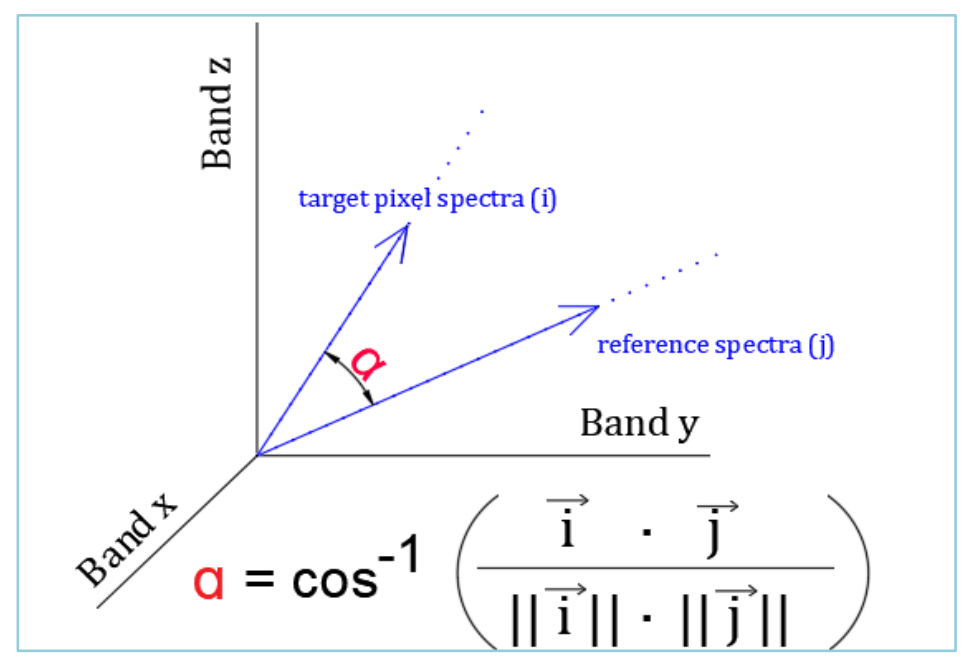

Fig. 10. Scheme of a 3D plot of a target and reference spectrum separated by alpha. Band values represented on axes $\mathrm{x}, \mathrm{y}$ and $\mathrm{z}$. 


\section{$L S U$}

The spectral linear unmixing, is a technique that considers each target pixel spectra as a linear combination of the endmember reference spectra, having a particular relevance when estimating the abundance of certain materials or minerals is the desired purpose. It presents two options for restriction: unrestricted unmixing or partially restricted unmixing. In this last one, the abundances can obtain negative values but the sum of the multiplication factors of each endmember is limited to one. The result of this process is a quantity estimation image for each endmember and an RMS error image to help determine the areas of the final members that are missing or incorrect.

\section{$M W L$}

The minimum wavelength mapper (MWL) algorithm (Bakker et al., 2011; van Ruitenbeek et al., 2014) is used to highlight/enhance variations in mineral abundances and identify random mineral and alteration phases in different absorption bands through specific ranges. By using in-house Python scripts (based on a toolbox developed by Jakob et al., 2018), the precise wavelength position of the absorption feature and its depth are mapped. This will provide us with insight into which material is in greatest abundance since there is a relation between the absorption depth and concentration.

\section{Band Ratios}

It is also possible to retrieve significant geological information using a relatively simple algorithm as a band ratio (BR), i.e. the division of the reflectance values of two selected bands marking the maximum and minimum of a certain distinctive absorption feature. Band ratios based on averages across multiple bands are more robust against noise than using single bands (Fig. 11). We use several spectral indices developed for ASTER data (Cudahy et al., 2008) that are sensitive to mica, chlorite, iron oxides and opaque minerals.

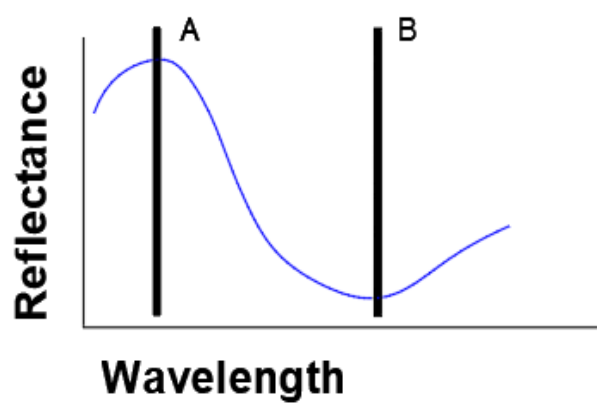

RATIO $\mathrm{Z}=\frac{\mathrm{A}}{\mathrm{B}}$

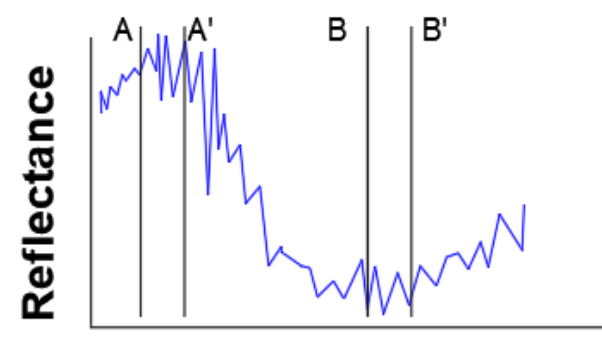

Wavelength

RATIO Z $=\frac{\mathrm{A}^{\prime} \mathrm{A}^{\prime}}{\mathrm{B}: \mathrm{B}^{\prime}}$

Fig. 11. Band ratio. The first figure and equation represent the most simplified and elementary form of the band ratio calculation. The second show the calculation for noisy spectral signals where we have to make an arithmetic mean to avoid taking extreme values that may lead to errors. 


\subsection{REFERENCE DATA (Spectral libraries)}

As it has been mentioned before, for supervised classifications there must be reference data with which the algorithm compares the target image and establishes similarity patterns. For these data integration, two different sources are available: (1) spectra measurements from the test sites; (2) point measurements belonging to a rock waste type classification made by the geologists of Atalaya Mining, the company currently operating the mining district.

\section{Test sites}

The test site reference data consists of separate spectral libraries (acquired by the different methods described in sections 21.1 and 2.1.2) whose endmembers or classes are those belonging to the test sites lithologies: gossan (G), massive sulfide (MS), stockwork (STK), argillic alteration (ARG), purple shales (PS), culm shales (CLM), and chloritic volcanics (CHL).

\section{- Image spectra}

For the airborne spectral library, pixels corresponding to each test site and for each of the three datasets (VNIR, SWIR, and LWIR) were extracted using the ROI ENVI tool. The median spectra of every lithology in each range was calculated; using this estimator (central position variable in a sorted data set) gives a more robust result as it eliminates the effects of possible edge pixels from the background that can mislead to erroneous values.

Number of pixels used for each end-member library:

- $\quad$ Spectral library in the VNIR domain (pixel size 0,6 m): $\mathrm{G}=30$; $\mathrm{MS}=30$; $\mathrm{STK}=42$; $\mathrm{ARG}=48 ; \mathrm{PS}=30 ; \mathrm{CLM}=42 ; \mathrm{CHL}=154$.

- $\quad$ Spectral library in the SWIR domain (pixel size 1,25 m): $\mathrm{G}=6$; $\mathrm{MS}=9$; $\mathrm{STK}=8$; $\mathrm{ARG}=9 ; \mathrm{PS}=4 ; \mathrm{CLM}=12 ; \mathrm{CHL}=25$.

- $\quad$ Spectral library in the LWIR domain (pixel size 0,9 m): $\mathrm{G}=9$; $\mathrm{MS}=12$; $\mathrm{STK}=16$; $\mathrm{ARG}=12 ; \mathrm{PS}=12 ; \mathrm{CLM}=16 ; \mathrm{CHL}=42$.

\section{* Field and Laboratory Hyperspectral libraries}

All individual field-based spectra were plotted and visually examined in order to eliminate erroneous records whereupon an arithmetic average was calculated.

- The mean spectra of FTIR spectral library are based on the following number of single spectra: $\mathrm{G}=12 ; \mathrm{MS}=14 ; \mathrm{STK}=13 ; \mathrm{ARG}=14 ; \mathrm{PS}=14 ; \mathrm{CLM}=14 ; \mathrm{CHL}=$ 13.

- For the PSR, the data over which it was built were the following: $\mathrm{G}=39$; $\mathrm{MS}=40$; $\mathrm{STK}=51 ; \mathrm{ARG}=37 ; \mathrm{PS}=43 ; \mathrm{CLM}=48 ; \mathrm{CHL}=65$.

The procedure pursued for the lab spectra measures was similar to the airborne: pixels from the HS image were extracted and a median was calculated.

- The Fenix camera scanned the following hand samples: 20200724_001 Chloritic volcanics, 20200724_002 Culm shales, 20200724_003, Purple shales, 20200724_004 
Argillic alteration, 20200724_005 Stockwork, 20200724_006 Massive sulfide, 20200724_007 Gossan (Fig. 12). XRD analysis was later performed on the same samples.

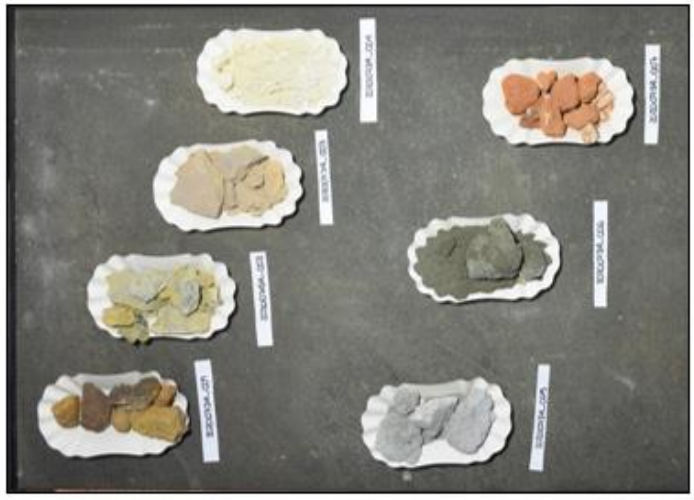

(a)

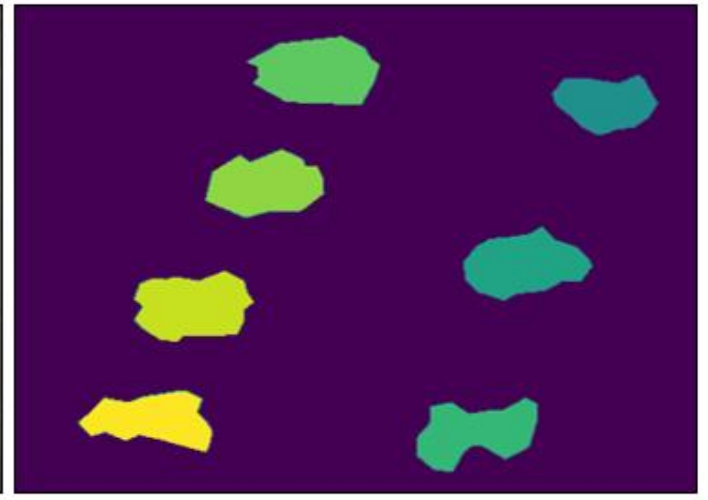

(b)

Fig. 12. (a) Fenix camera hyperspectral image of the collected test site hand samples placed in trays distributed along the table to maximise the detectable surface. First column and from top to the bottom: argillic alteration, purple shales, culm shales, chloritic volcanics. Second column and from top to bottom: gossan, massive sulfide, stockwork. (b) Polygons drown on the HS image and from which the pixels for spectral data were extracted.

\section{Rock waste types classification}

A total of six types of rock waste of the soil classification provided by Atalaya Mining are present in the target area:

- Pyritic stockwork with superficial oxidation waste type (STK). It constitutes the most abundant unit in the rock waste and corresponds to the outcrop of the mineralization that contained most of the stockwork. It has a high content of sulfur and oxides, presents an intense red colour and hydrothermal alteration processes.

- Pyritic stockwork with chloritic and sericitic alteration waste type (A-STK). This class comprises, as well as gossan to a lesser degree, felsic rocks and chloritic and siliceous alterations. It is variable in its sulphur content and its colour varies from grey to yellow.

- Massive sulfide accumulation waste type (MS). Derived from massive sulphide veins, some of them with a significant copper content.

- Gossan waste type $(\mathrm{G})$. This is presented as small accumulations on the surfaces of the waste units. Most blocks come from stockwork with low sulphur content oxidation areas.

- Slate waste type (SLATE). Variable unit in terms of origin and composition. Very low or nulo sulphur content, escombro inerte) and with colours ranging from brown and black to greenish and purple. Pueden presentar alteración caolinítica.

- Mixed waste waste type (MIX). This unit is the result of the combination of two or more of the waste types described above, mainly the oxidised stockwork and the altered stockwork or this second and slates.

The obtaining of the rock waste types classes characteristic spectrum was conducted in a practically identical procedure to that followed for the airborne spectral library or the test site lab library. On a stack that combines the three airborne hyperspectral data cubes (VNIR, 
SWIR and LWIR), a series of representative polygons (Fig. 13) containing the classes mentioned above were delimited on the map and characterized as Regions of Interest in ENVI. Subsequently they were converted into a spectral library that employs the mean of the collected pixels. The choice of the polygons was made based on two reasons: (i) The distribution of the rock waste types on the map of Atalaya mining, and (ii) the spectral consistency of the set of pixels chosen for each region.

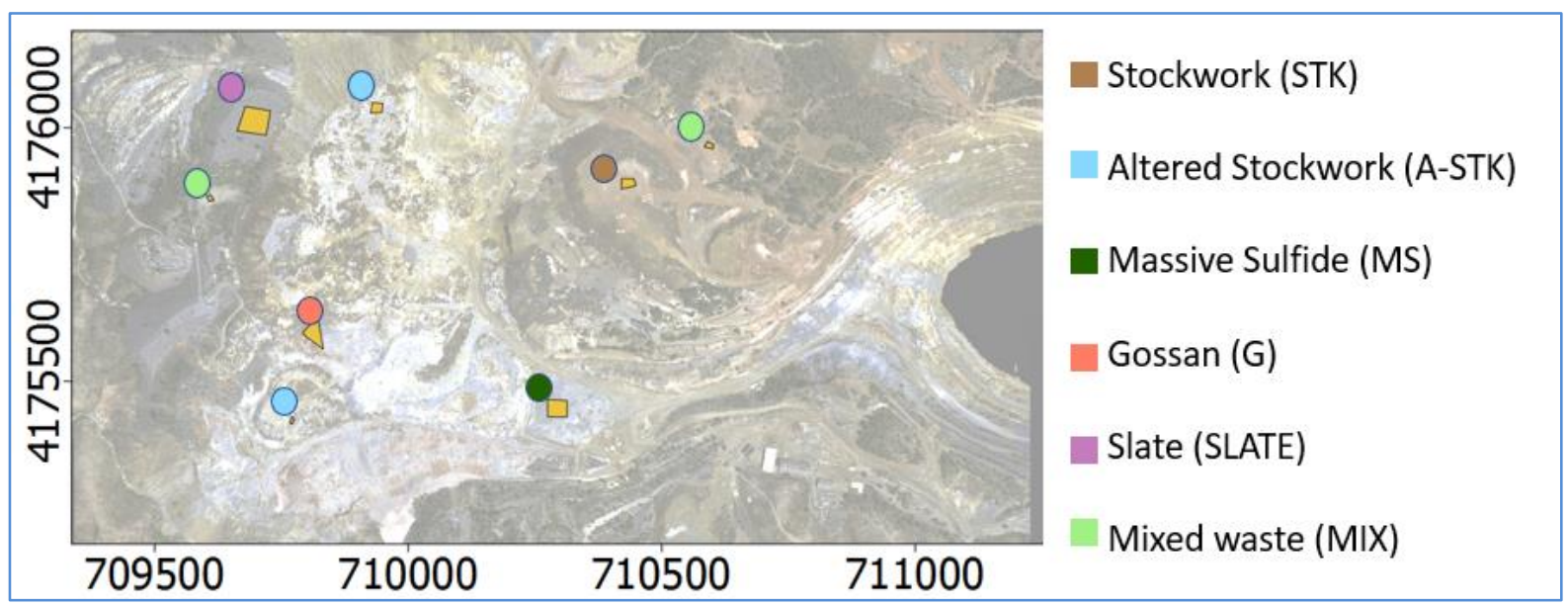

Fig. 13. Location of pixels extracted from the validation map of rock waste types to serve as ground-truth information/ input into supervised classification.

Number of pixels used for the rock waste type end-member library:

- Spectral library in the VNIR_SWIR_LWIR domain (pixel size $0.6 \mathrm{~m}$ ): STK = ; A$\mathrm{STK}=30 ; \mathrm{MS}=42 ; \mathrm{G}=48 ; \mathrm{SLATE}=30 ; \mathrm{MIX}=42$.

\subsection{VALIDATION DATA}

To evaluate the accuracy of the obtained HS results (SAM, LSU, bands ratios), they are compared to the map of rock waste types, which is supplied by Atalaya Mining. The validation vector map is first rasterized at the same resolution as the input image. Then all image values are extracted per rock waste type and visualized in probability histograms and box and whisker plots. 


\section{RESULTS AND DISCUSSIONS}

Due to the complexity of the working path followed and the diverse nature of the techniques and algorithms used, for a better understanding of the method, the presentation of results and their discussion will be done simultaneously. The development of this chapter can be divided into two consecutive and complementary sections. Besides, they are necessary to achieve the main objective of this thesis: the assessment of the effectiveness when using airborne hyperspectral images for mineral mapping.

- The first step is focused on the test site spectral library building and its interpretation. Subsequently, two different supervised techniques for mineral characterization are employed: Linear Spectral Unmixing and Spectral Angle Mapper. These classifications are made over an entire infrared wavelength range and require different reference data to ensure its effectiveness

- The second section proposes alternative approaches to gain an insight into the composition of the rock waste deposit, putting into practice the following methods: Minimum Wavelength Mapper and Band Ratios. As was anticipated, these two techniques target specific wavelength ranges.

In a parallel way, the results acquired are validated and contrasted. Finally, a general evaluation of the workflow followed, and the usefulness and validity of the methods and algorithms used is made. The maps presented within the results are projected on the WGS 84 /UTM zone 29N Coordinate Reference System (EPSG: 32629).

\subsection{TEST SITES LIBRARIES AND CLASSIFICATION ALGORITHMS}

\section{Test sites spectral library}

Fig. 14. shows the end-member library from the test sites extracted from the three airborne datasets. The figure is divided into three parts, one for each range (VNIR, SWIR and LWIR). Note that the wavelength and reflectance scale is different for each range. LWIR was converted into reflectance for a better understanding of the spectral signal behaviour through the entire infrared domain. Fig. 15. shows the test sites endmember library from the laboratory plotted in conjunction with the field spectra measurements. Fenix and PSR graphs cover the same range $(400-2500 \mathrm{~nm})$ showing a strong correlation between them. It is not the same if we compare the airborne spectra with the one obtained in the field or laboratory. The characteristics and absorption features will be preserved but the atmospheric effects will be very present.

In the VNIR range, diagnostic features for iron sulfates and iron hydroxide minerals can be found. The PSR lab spectra from the samples of the test site show typical Fe features mostly in the gossan, but to some extent also in the argillic, purple shale and chloritic sampes. For the massive sulfide and stockwork, the spectra are mostly flat. For the gossan sample high contents in hematite are most likely based on comparisons with library spectra (e.g., Crowley et al., 2003). This is confirmed by the XRD results. 


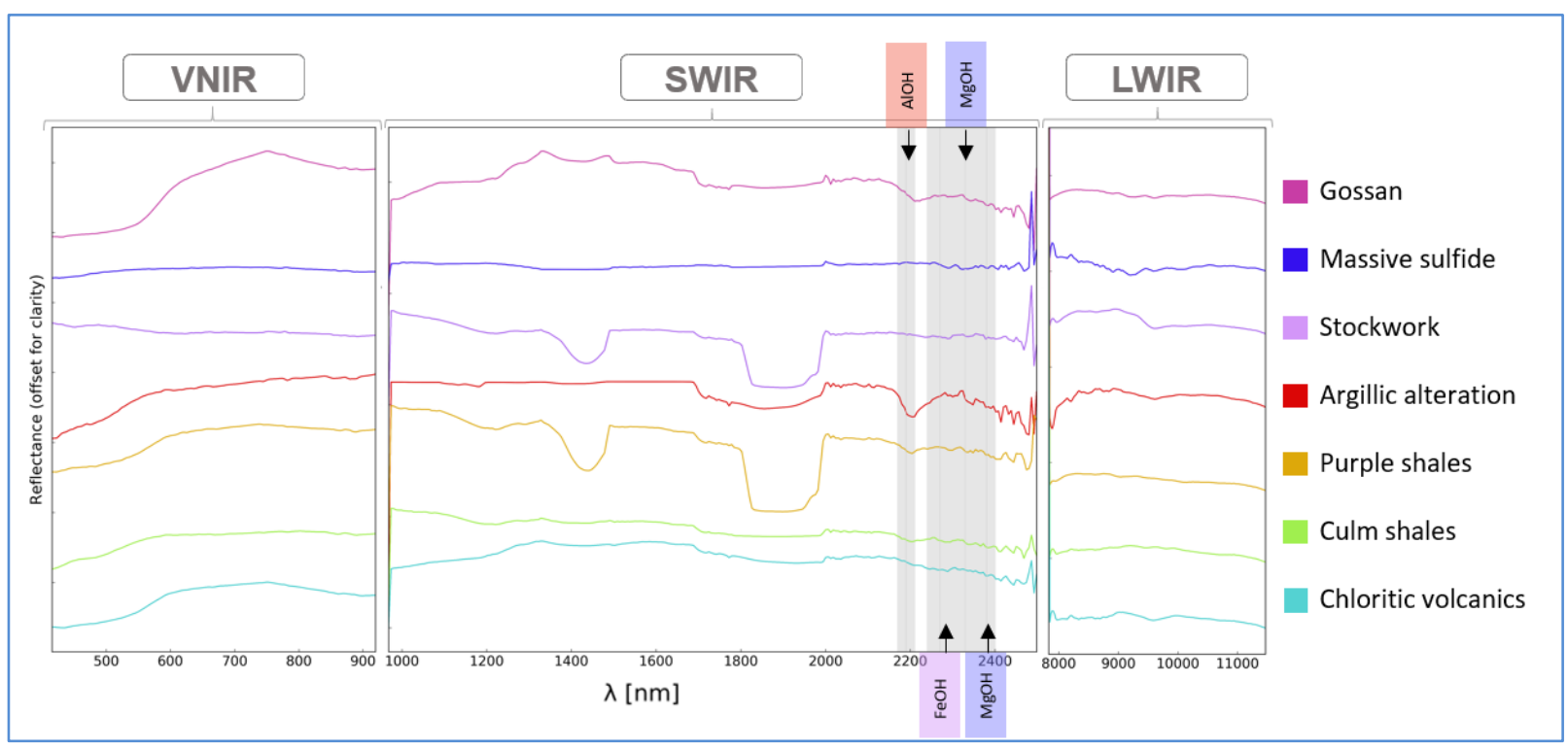

Fig. 14. Spectral library from the reference sites. Airborne VNIR (415.4-992), Airborne SWIR (968.4-2498) and Airborne LWIR (7800-11800).

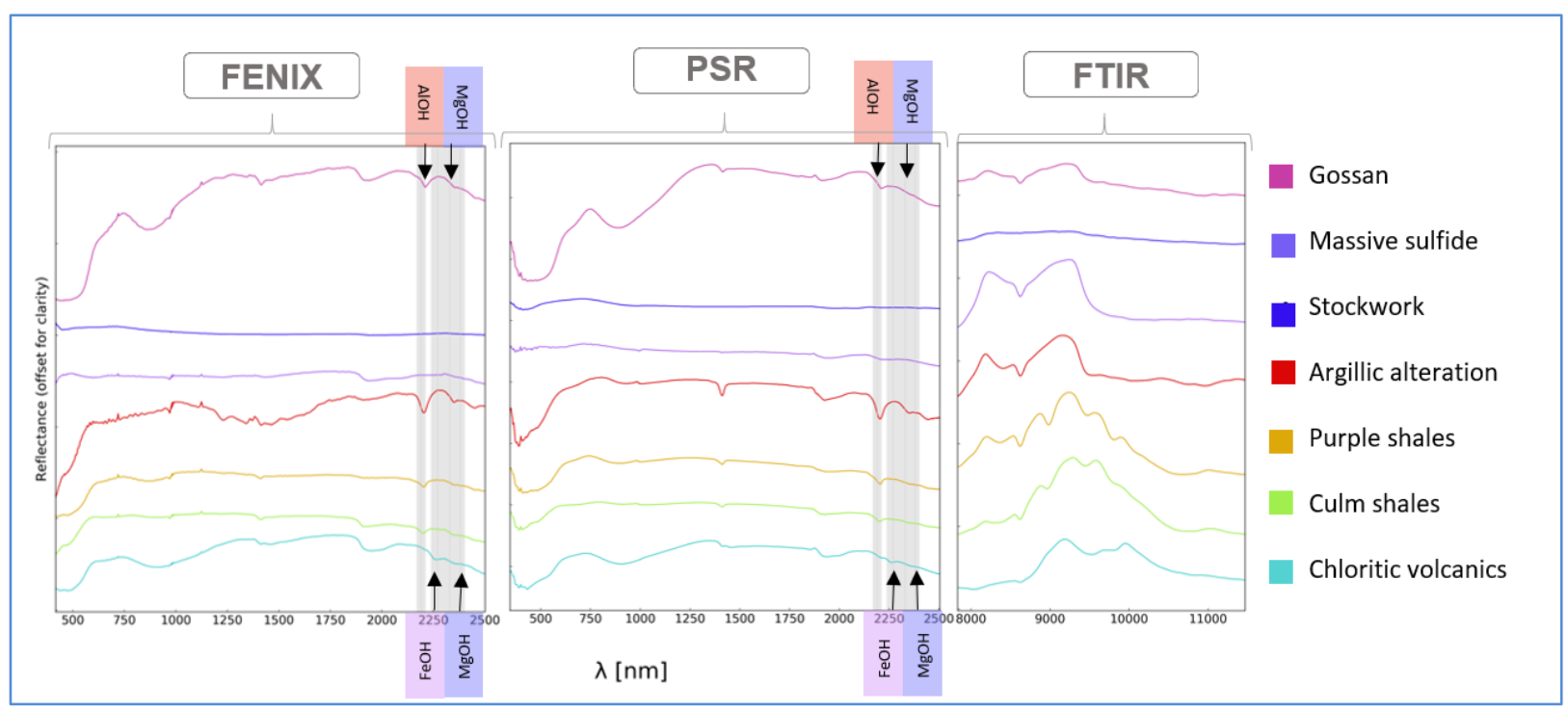

Fig. 15. Spectral library from the reference sites. Lab spectral Fenix Camera (378-2503), PSR (344.642500) FTIR (7800-11800)

In the SWIR range, we can distinguish pronounced point absorptions at different wavelengths that are indicative of characteristic element contents. Absorptions for $\mathrm{AlOH}-$ bearing minerals can be observed around $2200 \mathrm{~nm}$ for the gossan, the argillic, and the shales. The chloritic alteration has a minimum in the $\mathrm{FeOH}$ range around $2260 \mathrm{~nm}$. The argillic also shows pronounced water features at $1400 \mathrm{~nm}$ and $1900 \mathrm{~nm}$. These water features are more prominent in the airborne spectral library compared to the lab spectral library. This is due to atmospheric effects when data acquisition. For the massive sulfide and stockwork, the spectra are mostly flat.

The spectrum in the LWIR range shows a softer trend, without sharp absorption, spectra with broad features. Quartz features can be appreciated in stockwork, gossan and argillic lithologies because of dominance of this mineral abundance over other (spectrally active) 
minerals detectable in the LWIR range like pyroxene, feldespato, muscovite, garnet, apatite and chlorite. Chlorite and muscovite features present in $9.4 \mu \mathrm{m}$ are shown in argillic alteration, Culm shales and purple shales mostly. Once again, mostly flat spectra for massive sulfide with no distinguishable abstorions. On average, in comparison with FTIR spectra (Fig. 16.), the signal is subdued but characteristic absorptions are preserved.
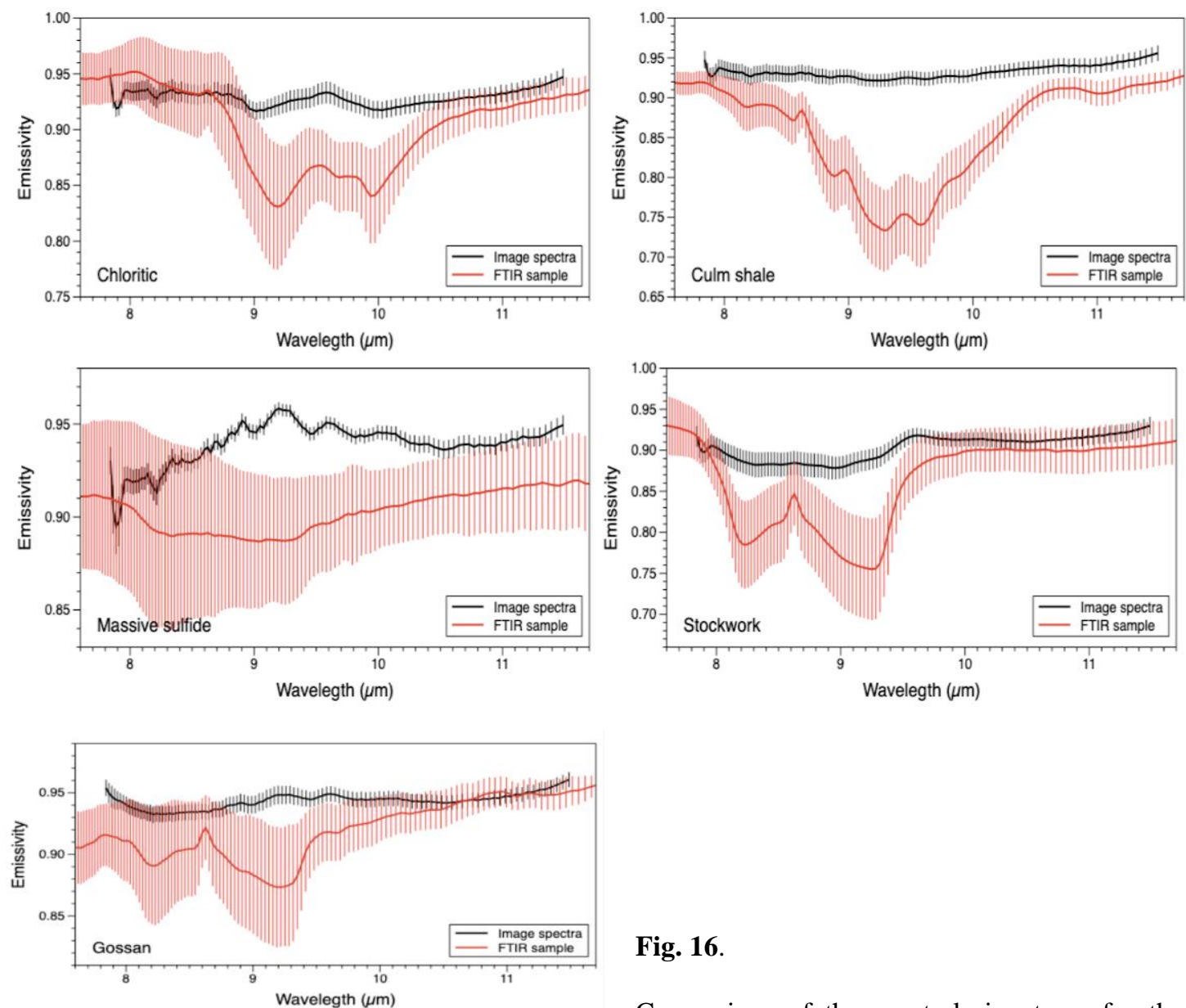

Fig. 16.

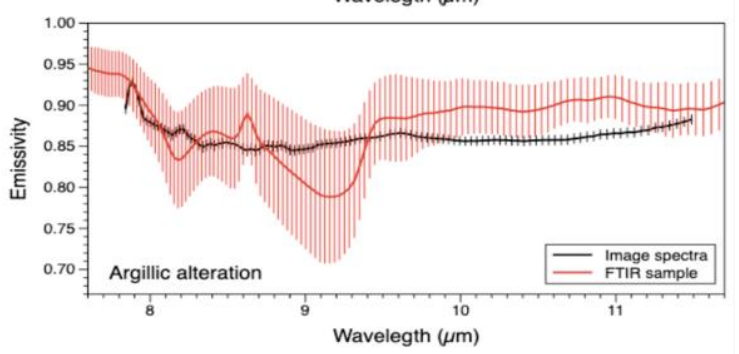

Comparison of the spectral signatures for the same lithologies obtained from different sources. Red = FTIR spectral signature. Black $=$ Airborne image spectra. Note that for a better integration of the measures, both radiance units are (normalized?) in emissivity. From left to right, top to bottom: Chloritc volcanics, culm shales, gossan. massive sulfide, stockwork and argillic alteration.

\section{Classifications algorithms}

In this chapter, two different approaches for utilizing airborne hyperspectral data for mineral exploration in rock waste deposits are evaluated: (a) using spectral unmixing based on "pure lithologies" as a means to identify high abundances of ore material in the rock wastes, and (b) mapping types of rock wastes (for resource characterization and environmental monitoring) using supervised classification methods as a means to extrapolate information from small, ground-truthed areas to larger, unmapped areas.

\section{LSU}

To map the abundance of the typical materials of the RT mine, particularly the ore-bearing lithologies, Linear spectral Unmixing technique using the test sites' spectral library as 
reference data is applied. The efficiency of mapping endmembers using different wavelength ranges is assessed.

Fig.17. shows the gossan, massive sulfide and stockwokr abundance maps obtained for the VNIR, SWIR, and LWIR datacubes. For a more detailed display of the linear spectral unmixing imagery, including the abundance maps for all endmembers and an RMS image estimating the incurred RMS error in each domain, see Appendix (A.3). Abundance values are represented in a grey scale, ranging from black to white with the latter corresponding to maximum abundance.
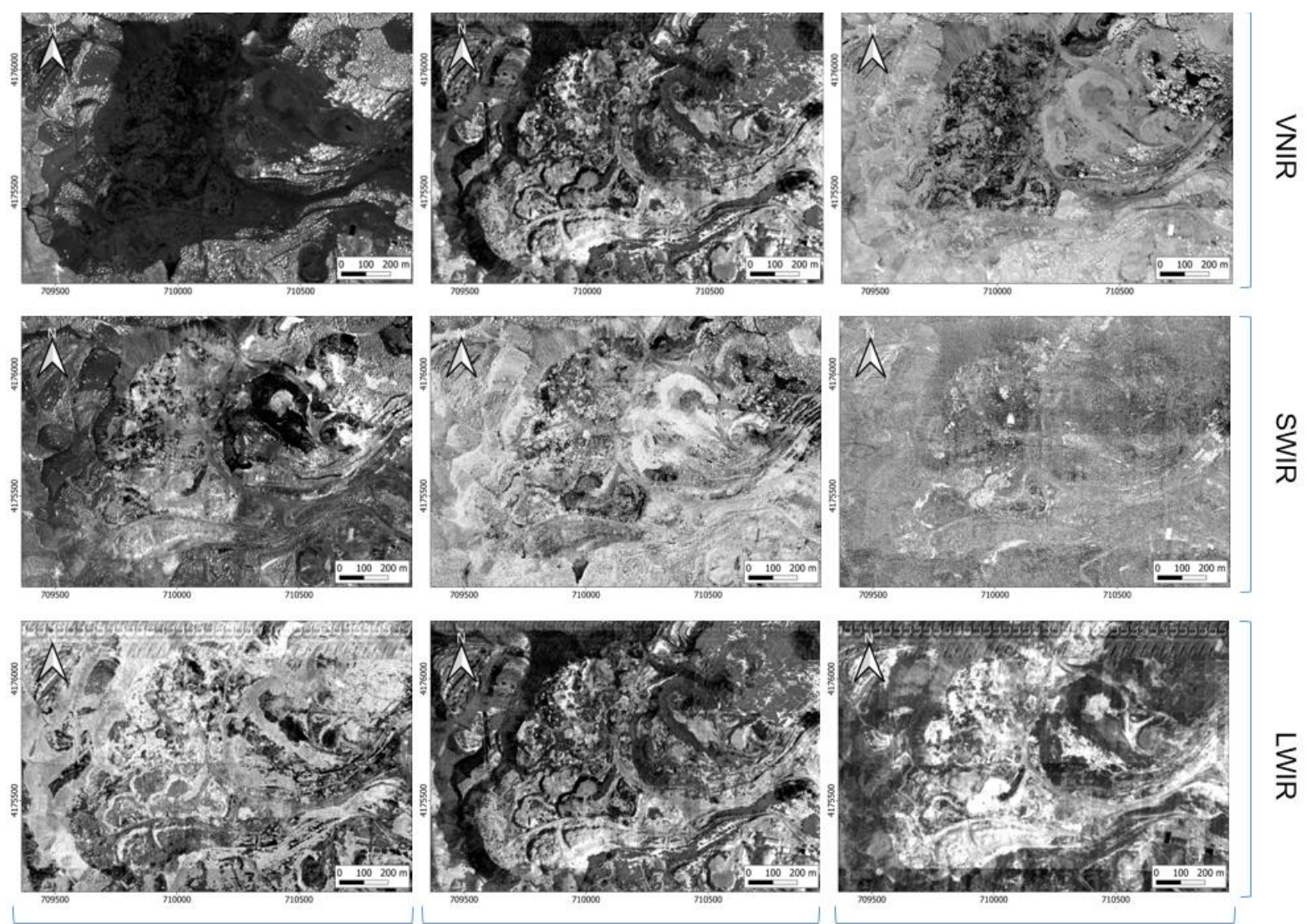

GOSSAN

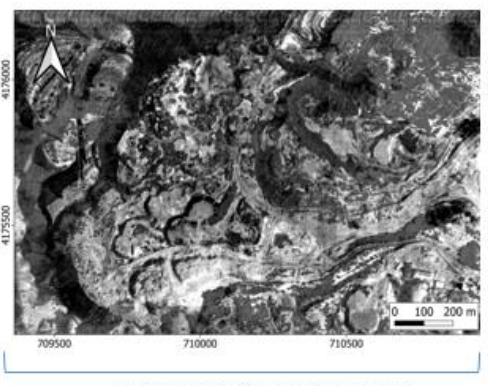

MASSIVE SULFIDE

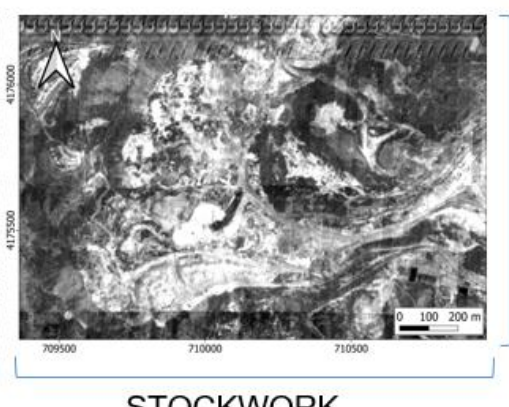

$\sum_{j}^{\nwarrow}$

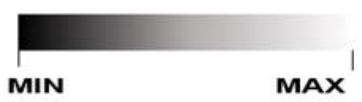

Fig. 17. Linear spectral unmixing for Gossan, Massive sulfide and Stockwork based on VNIR, SWIR and LWIR HS datacubes, respectively.

We will mainly be interested in the abundance of the ore mineralizations which include massive sulfide, stockwork, and gossan. However, we also know that the chloritic alteration is usually associated with stockwork so its estimation can be used as a proxy. The rest of the lithologies (argillic alteration, purple, and culm shales) are considered to be sterile in terms of economic value or environmental threat, but it is not out of place to have an estimation of quantities and distribution along the rock waste.

For the VNIR maps, a pattern is reproduced in all images, being easier to distinguish in stockwork and massive sulfide: Halfway down in the image we see a sharp in tonality which may be the result of the atmospheric distortions or, most probable, overlapping when mosaicking the individual images that conform the whole area. In the SWIR range, the stockwork abundance map is quite noisy and there is a low pixel continuity. In the LWIR 
imagery too many patches and aerial artifacts interfere leading to misclassifications. The RMS error for this range is unacceptable (Appendix A3).

In order to compare in a quantitative way the obtained abundances with the ground truth data, and thus to assess the effectiveness of this tool when estimating quantities and target mineral distribution, validation graphics were performed (Fig.18). This graph shows the distribution of the estimated abundance of each of the pure lithologies (gossan massive sulfide, stockwork) along the different rock waste types for every range. We obtain a poor correlation in which we neither distinguish nor are able to make associations or partnerships between the rock waste types and the presence of determined pure lithologies.
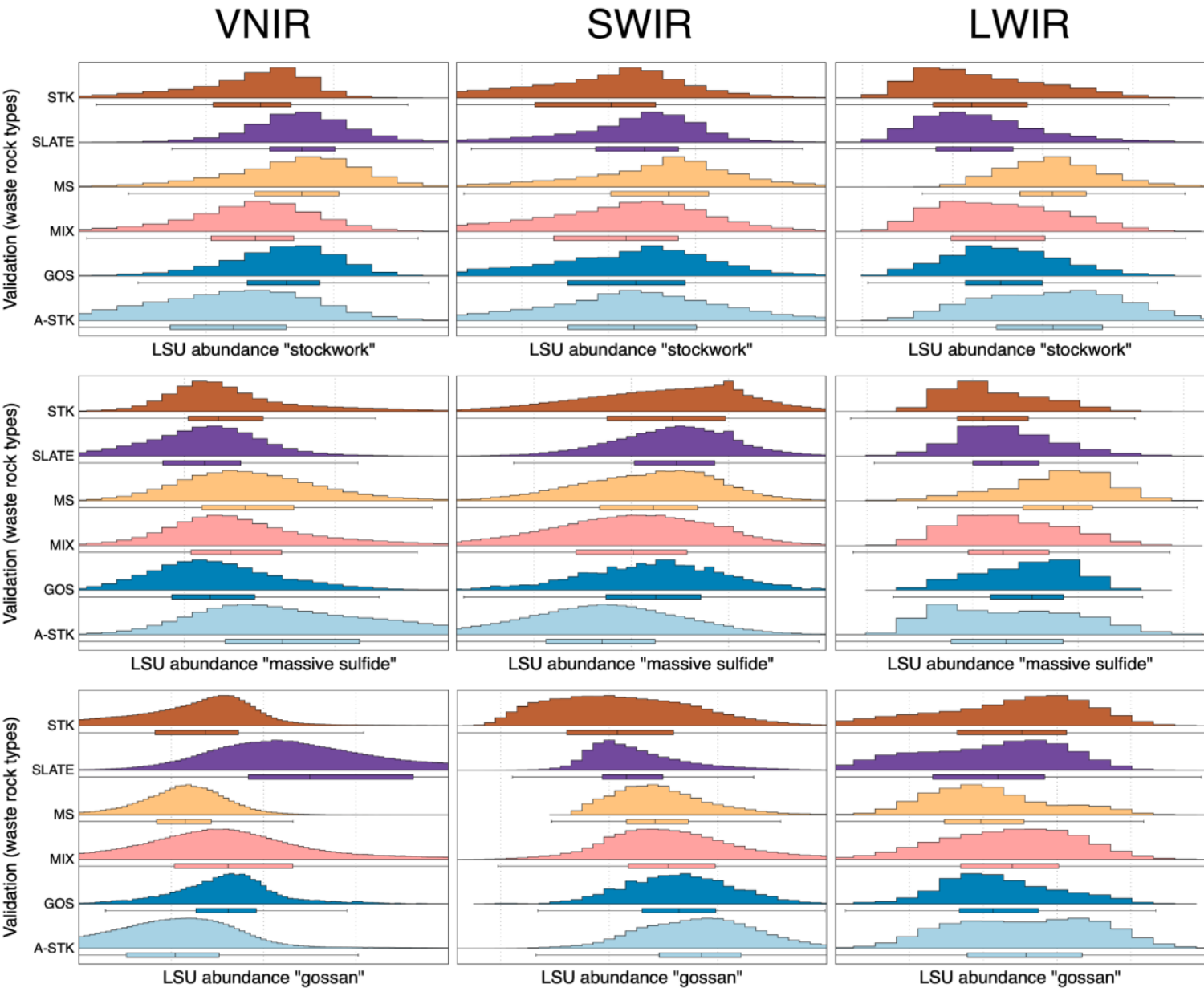

Fig. 18. Validation charts showing the abundance and distribution estimated of the stockwork, massive sulfide and gossanfor each rock waste type in every range (VNIR SWIR and LWIR).

One of the reasons behind this is that minerals possess their characteristic features absorptions in different specific parts of the infrared EM spectrum. This means that depending on the range we are in; some minerals will be identified, and others will be unnoticed. For this technique to be effective, it is strongly recommended using a stack that combines all the wavelength ranges we have available information on. The other reason is quite obvious, high RMS error values (Appendix A3) and visible external patches, marks, and noise in the images contribute to misleading classifications.

\section{SAM}

Since the spectral library extracted from the test sites corresponds to 'pure' lithologies, may significantly differ from the actual composition of the target pixels found in the rest of the 
mining area, especially in the rock waste. SAM assigns each pixel to its predominant lithology, being pointless using these 'pure lithologies' as endmembers when we are dealing with mixed pixels. For this purpose, the rock waste types library is used as a means to extrapolate types of waste rock to larger areas (Section 4.4 Reference data. Rock waste types) (Appendix A4).

The HSI dataset on which these classifications are being conducted is a stack that combines the three airborne cubes, VNIR, SWIR, and LWIR. NDVI (vegetation) and slope masking was performed to avoid possible misclassification. The end-memebers employed are: Pyritic stockwork waste, altered pyritic stockwork waste, mixed waste, slate waste, massive sulfide waste and gossan waste.
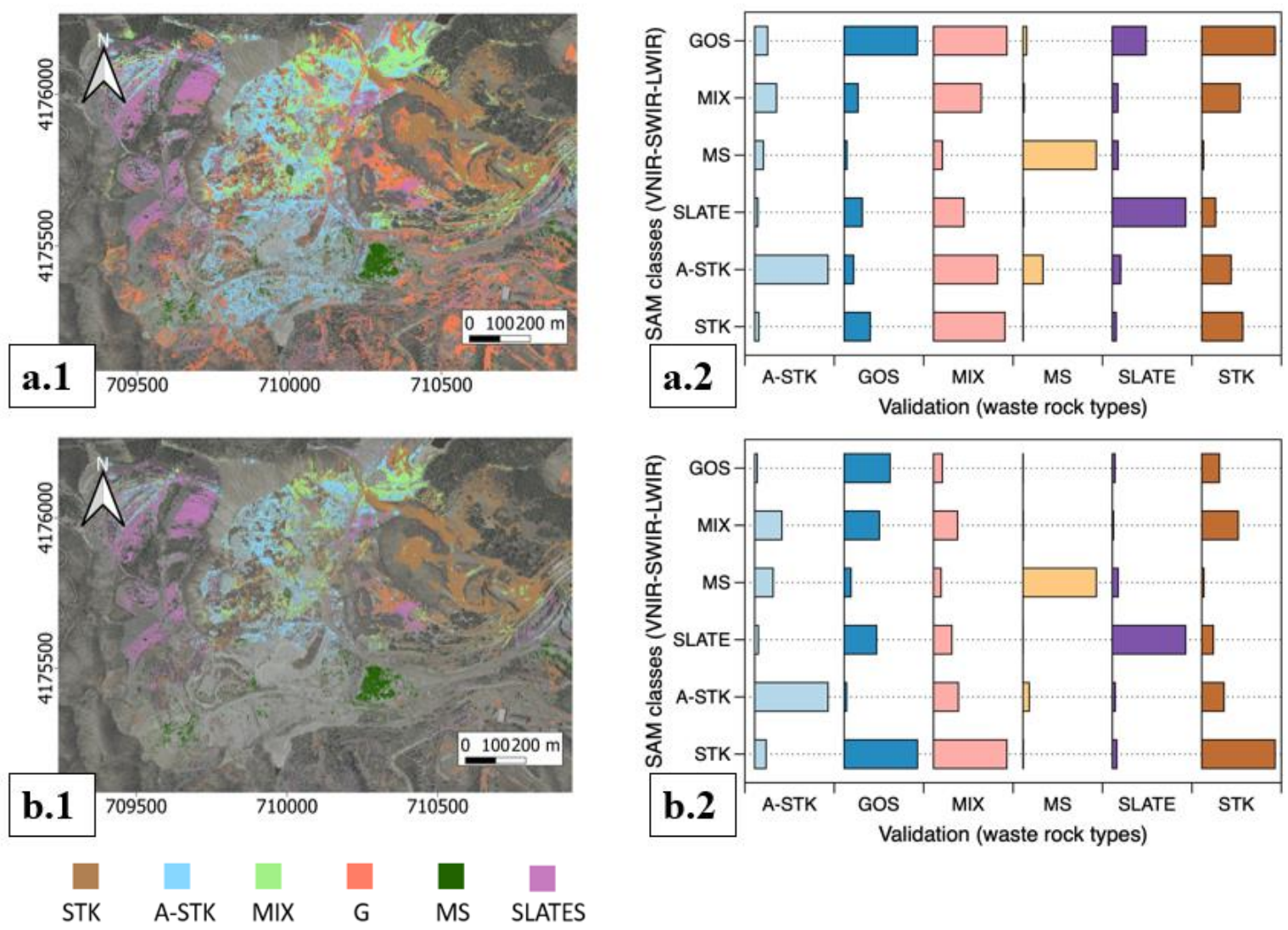

Fig. 19. a.1 SAM supervised classification for the six rock waste types using an angle $=0.1 \mathrm{rad}$. a.2 Validation chart comparing the previous SAM with the ground truth rock waste types classification. b.1 SAM supervised classification for the six end-members rock waste types using a different angle for each: STK=0.0864 rad; A$\mathrm{STK}=0.0802 \mathrm{rad}$; MIX=0.0936 rad; SLATE=0.0888 rad; MS=0.1158 rad; GOS=0.0658 rad. b.2 Validation chart comparing the b.1 SAM with the ground truth rock waste types classification.

Fig. 19. a.1 presents a SAM using an equal threshold angle $(0.1 \mathrm{rad})$ for each of the occurring endmembers. The vast majority of pixels are classified. The central part of the rock waste contains homogeneously mixed pyritic stockwork, altered stockwork and mixed stockwork units. There does, however, seem to be an area in the right corner where a massive sulfide unit is concentrated. It is interesting to note how in the lower part of the image we do not find such a variety of classes and not all pixels are categorized, which leads us to consider that there is somehow either an overestimation of the blue and orange classes, (A-STK) and (G) respectively, or an underestimation of the rest. 
As in the previous section, to compare the obtained distribution with the ground truth data, and thus to assess the effectiveness of this tool when extrapolating reference point measurements to larger zones, a validation was made.

Considering the validation graph (Fig. 19. a.2), we can suggest that some of the rock waste types are misclassified, especially pyritic stockwork and mixed stockwork. This may be caused by choosing a higher angle value when building the SAM. In the following approach, this classification method has been fine tuned:

Rule map images resulting from this first SAM classification helped to assist in determining a more accurate angle for each class. Histograms showing the distribution of pixels over the range out of the rule images were plotted and the angle value corresponding to the inflection point of the curve's slope for each class was chosen. In this way, figure 19.b.1, presents a new enhanced SAM resulted at a different angle for each endmember: STK=0.0864 rad; A-STK=0.0802 rad; MIX=0.0936 rad; SLATE=0.0888 rad; MS=0.1158 $\mathrm{rad}$; GOS $=0.0658 \mathrm{rad}$.

This time, in the lower part of the map most of the pixels are not classified (Fig. 19 b.1). According to the validation graphs (Fig. 19 b.2), the correlation for stockwork, massive sulfide and slates is reinforced, however, for the gossan seems to introduce further errors. Inaccuracies or small variations in classifications can come out of two sources: (i) similarities in the spectra of two waste types, (ii) mixing zones of these.

In general terms, SAM seems to perform quite well. Both maps follow a similar pattern to the one in the VNIR and LWIR linear spectral unmixing, this leads us to think that the misclassifications and underestimation have not the origin in the spectral libraries used as reference data but in the raw image itself, especially in one of the earliest stages: the VNIR and LWIR individual mosaicking. It should be further discussed at some length.

\subsection{ALTERNATIVE APPROACHES}

These algorithms supported by simple mathematical methods enhance the importance of the local geology and mineral spectroscopy understanding. They are targeted at specific ranges, so knowing the spectral response of minerals in the target area help us to know in which range can be identified.

\section{Minimum Wavelength Maps.}

Shifts in wavelength position may be highly relevant to hyperspectral remote sensing. In order to identify the most relevant mineral phases, 2 minimum wavelength maps in different ranges of the EM spectrum have been carried out. Wavelengths ranges have been chosen in line with previous knowledge and understanding of the particular geology of the area, a Volcanic Massive Sulphides system (VMS). According to the map legend, the colour corresponds to the wavelength position of a certain absorption feature, and the intensity reflects its depth.

Figure 20.a shows the MWL corresponding to the SWIR domain, between 2150 and 2400 $\mathrm{nm}$. In the image, we can distinguish the existence of four major colours which will therefore be associated with the presence of four predominant minerals distributed over the area. 
Blueish colors are predominant in the image occupying the central part of the rock waste, they represent maximum absorptions around $2200 \mathrm{~nm}$. This being an indicator of $\mathrm{AlOH}$ content, which is very abundant in minerals such as white micas. White micas are common minerals resulting from the alteration in mineralised bodies such as the Volcanogenic massive sulphide ore deposit. In the XRD, there is a high presence of mica in culm and purple shales and argillic alteration. The rock waste periphery presents a greenish colour that can be easily related to the presence of chlorite, whose deepest absorptions are located at 2250 and 2350 $\mathrm{nm}$ due to its content of $\mathrm{FeOh}$. Absorption features between 2310 and $2350 \mathrm{~nm}$ are caused by $\mathrm{Mg}-\mathrm{OH}$ and $\mathrm{CO} 3$ bond stretching, and thus, alteration minerals such as, chlorite, biotite, epidote and carbonates exhibit characteristic absorption features within this range [ref], compounds that characterize chlorites. The entire surface layer of RT which is maily chloritic alteration is composed of 50\% chlorite (see XRD). Purple colours can be related to the existence of kaolinite, a mineral that presents sharp absorptions in both 2165 and $2186 \mathrm{~nm}$. According to the XRD there is not much existence of kaolinite, especially and to our surprise in the argillic alteration which is where we expected it since belonging to the clay group, kaolinite is a key mineral in the argillic alteration identification. Furthermore, all the pixels showing kaolinite are located in slope zones (based on MDT model) which can yield to erroneous values so they can be false indicators.

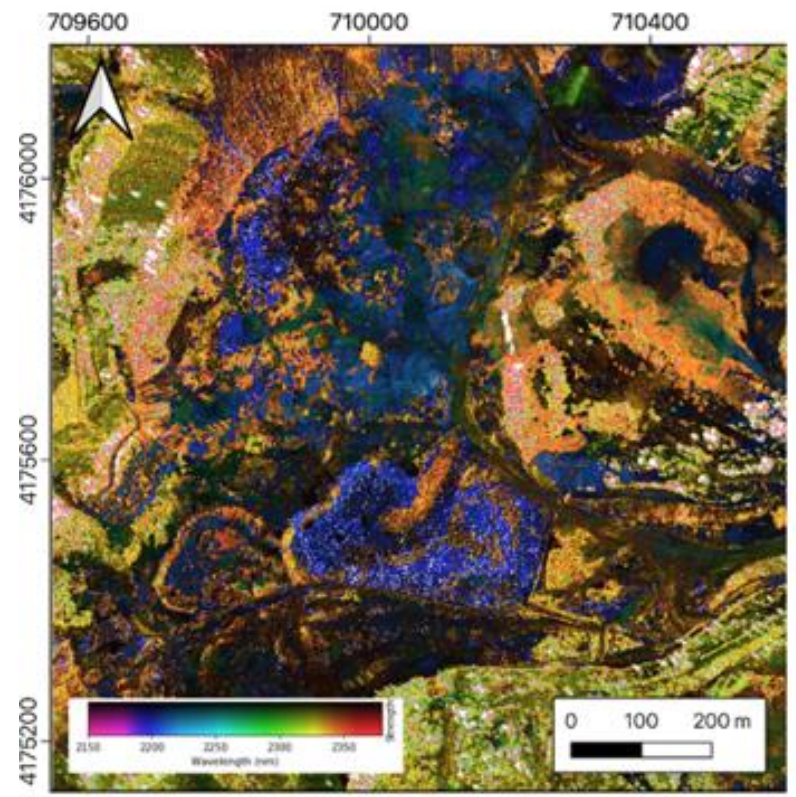

(a)

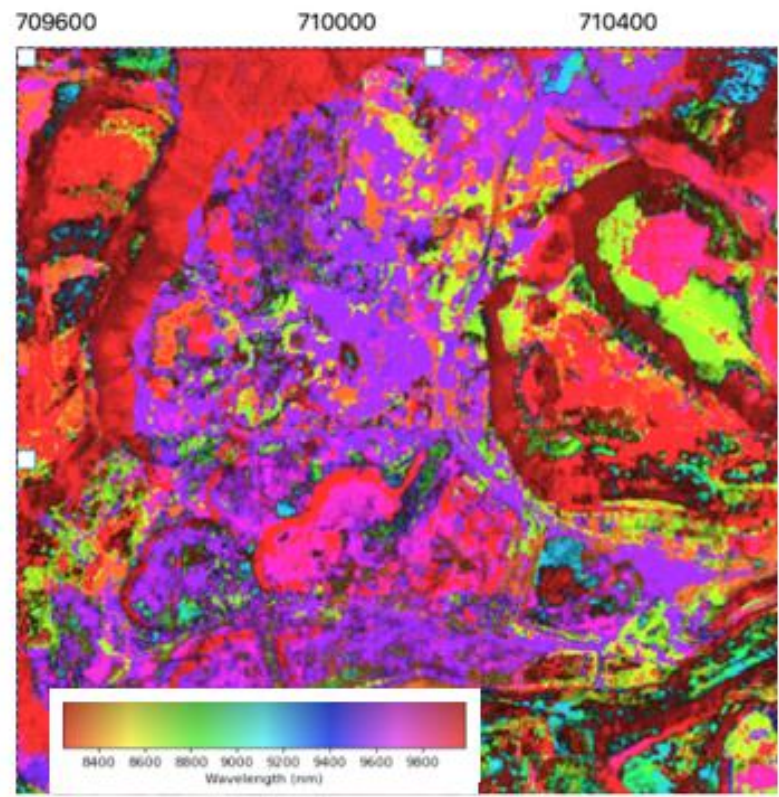

(b)

Fig. 20. (a) Minimum wavelength map (2150-2400 nm) based on short-wave infrared hyperspectral image showing wavelength of deepest absorption feature of the Corta Atalaya rock waste deposit to evaluate the content of alteration mineral content. Blueish colors $=$ white mica-dominated pixels, purple $=$ kaolinite, green $=$ chlorite. (b) Minimum wavelength map $(8.25-10 \mu \mathrm{m})$ based on long-wave infrared hyperspectral image showing wavelength of deepest absorption feature of the Corta Atalaya rock waste deposit to evaluate the content of alteration mineral content. Blueish colors $=$ chlorite and muscovite-dominated pixels, pink colors = kaolinite, greenish colors $=$ quartz.

Figure 20.b shows the MWL map for the specific LWIR range between 8.25 and 10.0 $\mu \mathrm{m})$. Reddish colours will be ignored as they are on either end of the spectrum, so they do not provide any information. Small yellow-greenish areas spread around the rock waste, correspond to quartz-bearing lithologies as quartz feature absorption presents its minimum around $8630-8633 \mathrm{~nm}$. Kaolin is represented by the colour pink as its feature absorption is around $9.8 \mu \mathrm{m}$; this time is distributed in the plateau highest zones, the possible distortion 
caused by this topographic feature has yet to be evaluated. Chlorite and Muscovite share a feature absorption around $9400 \mathrm{~nm}$ due to the presence of the $\mathrm{AlOH}$ phase and cannot be distinguished from each other, on the map this phase is represented by the blue to purple colours. These two minerals are the most abundant in the rock waste, being present in almost all the lithologies described above but massive sulfide mineralization (see XRD analysis). Albite also presents an absortion in 9.4 but we can practically ignore it because, once again, relying on the XRD analysis, it only constitutes a small part of the composition of the culm shales.

For both maps, as the areas corresponding to step slopes have an homogeneous color, it is proposed that these areas introduce a topographic distortion and possibly lead to misclassifications.

\section{Band Ratios.}

Minerals have distinctive absorption features through the electromagnetic spectrum. The thresholds used in the process are subjective and scene dependent so the ratios need to be selected on the basis of critical parameters. Considering the prior knowledge of the target area, the following ratios were calculated: Iron index, Opaque index, Ferric oxide composition index, AlOh Group index, and quartz index. These provide us with an overview of the content and distribution of the same in the rock waste (Fig. 21).

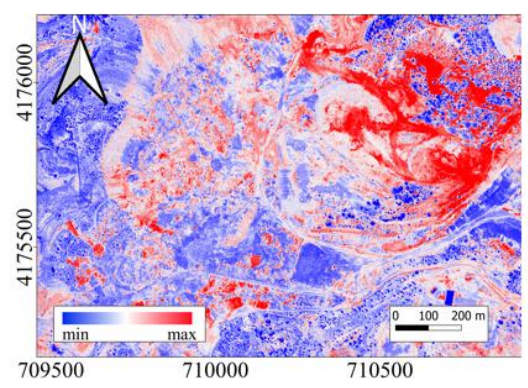

Fe oxide composition (630:690/520:600)

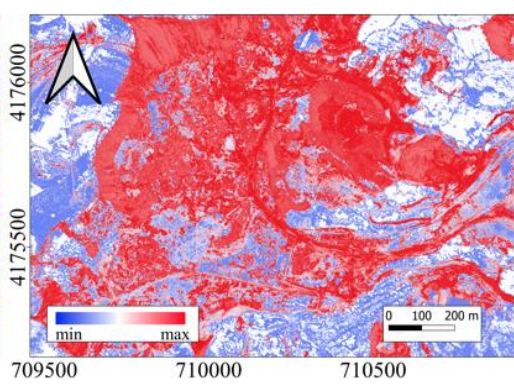

Fe index $(740: 760) /(850: 890)$

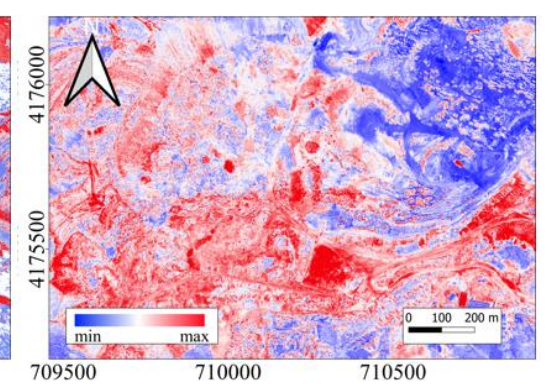

Opaque Index (520:600)/(1600:1700)
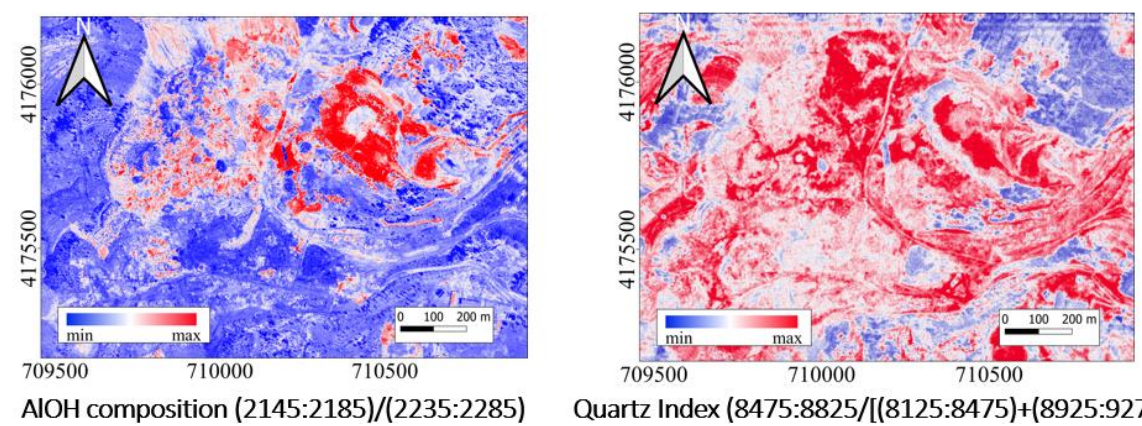

Quartz Index (8475:8825/[(8125:8475)+(8925:9275)]

Fig. 21. Upper images: Ferric oxide composition index based on band ratio of (630:690/520:600). Iron index based on band ratio of $(740$ to $760 \mathrm{~nm}) /(850$ to $890 \mathrm{~nm})$ and Opaque index $(520$ to $600 \mathrm{~nm}) /(1600$ to 1700 $\mathrm{nm})$. Lower images: AIOHcomposition based on band ratio of $(2145$ to $2185 \mathrm{~nm}) /(2235$ to $2285 \mathrm{~nm})$ and Quartz index of (8475 to $8825 \mathrm{~nm}) /[(8125$ to8475 $\mathrm{nm})+(8925$ to 9275$)]$.

Ferric oxide composition index (630:690/520:600) highlights hydrothermally altered rocks that have been subjected to oxidation of iron-bearing sulphides (L3 Harris Geospatial Solutions, n.d.). The interest in determining the presence and distribution of oxidised ferrous materials is evident: our work area is a rock waste of massive sulfides open pit. Thus high values of iron oxide can be regarded as proxies for massive sulfide, stockwork, and overall gossan. 
Fe index (740:760 $\mathbf{n m}) /(850: 890 \mathrm{~nm})$ :highlighting areas of high iron hydroxide and sulfate content. Detected in the VNIR domain, it leverages the difference between the ferric iron $(\mathrm{Fe} 3+)$ reflectance peak and ferrous iron $(\mathrm{Fe} 2+)$ absorption feature induced by crystal field transitions (Clark, 1999). Highlighting iron-rich areas, on a scale from blue to red, with red being the maximum concentration value, will be a good indicator of possible ore bodies existence. We may appreciate zones where it is more concentrated and others where it seems to be more disseminated. Note that the red patches where the distribution is more homogeneous correspond to slope areas and hence yield false positives.

Opaque index $(520$ to $600 \mathrm{~nm}) /(1600$ to $1700 \mathrm{~nm}$.): This band ratio calculated through the VNIR and SWIR range. Is a useful measure of reduced rock. Opaque minerals such as sulfides are sensitive to strong absorption at all optical wavelengths (Cudahy et al., 2008). It appears to be more content of opaques in the lower part of the rock waste and to a lesser extent in the right corner. Two circular areas in the middle of the map and a larger one on the lower right part can be easily distinguished due to their strong signal.

Quartz index (8475 to $8825 \mathrm{~nm}) /[(8125$ to8475 $\mathrm{nm})+(8925$ to 9275$)]$ : being one of the most common minerals on earth, quartz, has a unique spectral feature in thermal infrared. It displays a very pronounced absorption near $8630 \mathrm{~nm}$ between two peaks of $8230 \mathrm{~nm}$ and $91300 \mathrm{~nm}$. According to the distribution map, it can be noted that quartz is a predominant material (red) in the zone, also as indicated by the XRD analysis being present in most of the mineralizations with the exception of ore bodies and gossan (see XRD), so its absence (blue areas) can serve as a proxy for these lasts.

AIOH composition (2145 to $2185 \mathrm{~nm}) /(2235$ to $2285 \mathrm{~nm})$ : It seems to be more abundant in the upper part of the image, can be related to the presence of slates and alteration.

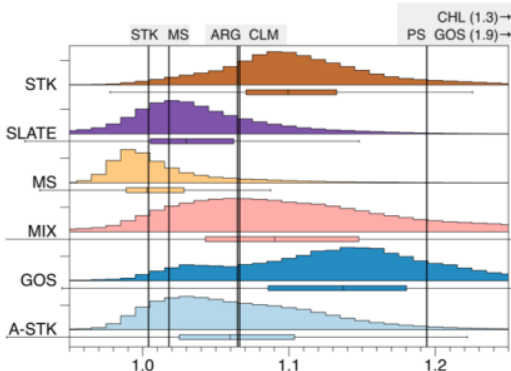

Ferric oxide composition
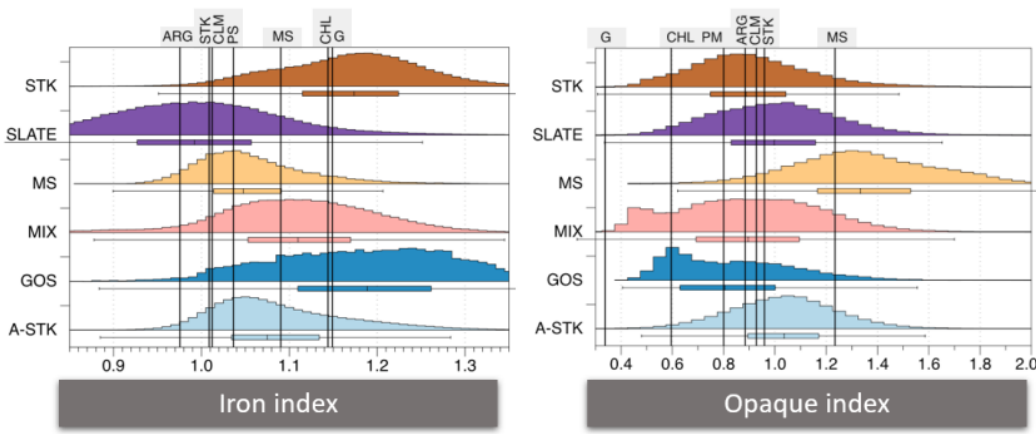

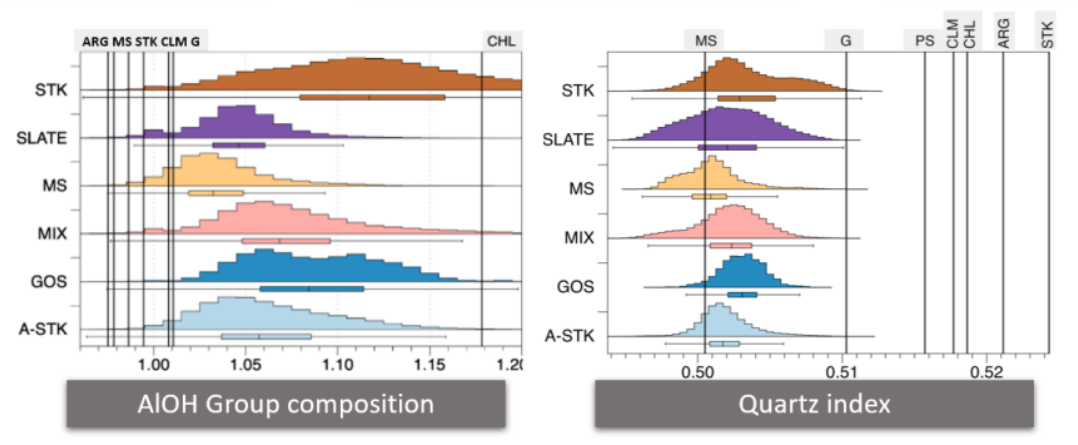

Fig. 22. Validation for the band ratios displayed in Fig. X (above). Lines refer to band ratios calculated from the average spectra of the test site endmember lithologies. Note the good separation between waste rock types for most of the indices and the good correlation between band ratios of mapped waste types and test site lithologies. 
The integration of the BR maps combined together with the validation data constituted by the waste types classification, and the BR calculated from the Fenix spectra measures of the test sites, considered as 'pure lithologies' contributed to the better interpretation of the remotely-spectral information which increases the reliability of the results (Fig. 22).

The ferric oxide composition band ratio turns out to be a good discriminant for the detection of pure lithologies as chloritic volcanic rocks and gossan especially, the latter having a band ratio value of 1,9 meaning a sharp slope between the two sets of bands. Therefore, for ferric oxide composition band ratio values around this value, we can practically guarantee that it would be pure Gossan. When it comes to the rock waste types classification, it seems consistent that the gossan waste type shows also higher band ratio values but is not comparable to the gossan of the test site since it is probably mixed with other materials. Lower BR corresponds to the ore, either Massive sulfide, and stockwork of the pure lithologies or Massive sulfide of the waste classification. There is a strong correlation between the Ferric oxide BR calculated for the massive sulfide unit from the waste classification and that of the test sites.

For the iron validation, two points should be highlighted: in terms of the rock waste types classification, the groups that seem to have the most iron content are the Pyritic Stockwork and the Gossan. On the other hand, it may be noted that for pure lithologies, the ratio of massive sulfide, and stockwork is very low when, according to XRD, its composition is mainly pyrite, especially for the MS (93\%). This low ratio may be due to the alteration in the stockwork of pyrite to $\mathrm{FeOH}$ phases and $\mathrm{Fe}$ sulfates.

The opaque index seems to be a top discriminant for the massive sulfide, whose characteristic BR value coincides for both classifications (rock waste type and test sites). We can affirm that from an index value of 1.3 onwards, we would almost certainly find Massive sulfide..It should be pointed out that gossan in both classifications appears to be the one with the least opaque content which can be quite disconcerting as the XRD analysis shows almost $50 \%$ of hematite, a metallic mineral; Due to the large iron feature present in hematite, this mineral is not considered spectrally opaque. the lower values of the two categories correspond to Massive sulfide.

For the ALOH compositon index, an outstanding separation for the Chloritic Volcanics lithology from the test sites is given. It's known they are usually associated with stockwork, so it is a lithology worth considering. Regarding the rock waste types classification, the pyritic stockwork with Chloritic alteration is the one presenting a higher band ratio value, but it is also well sorted along the BR values axis meaning that not all that unit have this high composition of $\mathrm{AlOH}$.

For the quartz index, excellent distinction for the Massive sulfide from the other test sites lithologies is shown. This test site-massive sulfide BR coincides with the median value of the Massive sulfide from the waste types classification, making a good match. The slate waste group, which is very abundant and varied, may interfere a little, but we can use other BR values to distinguish between the two, such as the iron oxide content, which is present in the slate, but not in the massive sulfide, or the opacity index, which is the opposite. 


\section{CONCLUSIONS}

\section{A short summary of the main outcomes and conclusions of this work:}

- The test sites end-member spectral libraries from the different sources (airborne remote sensing, field and laboratory) are robust and consistent with each other.

- The feature absorptions presented of each lithology can be easily related to the expected ones according to its mineralogical analysis (XRD).

- The characteristic spectrum of each reference lithology is sufficiently distinctive to be considered as different spectral endmembers.

- For this case of study, using the test sites end-member library as input for supervised classifications is only meaningful when estimating quantities.

- Results obtained from LSU are not satisfactory, this may be due to errors in preprocessing and preliminary steps when correcting the raw airborne datasets. On the other hand, it has been demonstrated that, along the different spectral ranges, the abundance estimation for the same materials are completely different; suggesting that the best way to integrate this unmixing tool would be using a stack combining all infrared ranges thus no material is overestimated or overshadowed by others.

- In a rock waste area, as the mixture of materials is highly heterogeneous, it is more appropriate to map mixed classes rather than 'pure lithologies'.

- Employing such relatively simple, expert-guided algorithms such as MWL and BR in this example yield much better discrimination of materials than naive classification methods that use the entire spectrum as an input.

- In the pursuit of ore-bearing minerals not only the two main lithologies (massive sulfide and stockwork) are subject of interest, but some others that can be used as a proxy must be considered, e.g. chloritic volcanic rocks and gossan.

- Accurate knowledge of the method and the local geology will allow us to refine and implement these techniques in a satisfactory way.

- This study enhances the importance of an interdisciplinary approach between remote sensing and geology, enlightening that in no means we can prescind from expertise geologists. 


\section{Limitations}

Throughout the development of this study, different limitations and challenges have emerged. In the first place, the airborne HSI datacubes used in this study were preliminary and were partly affected by high noise and artefacts, so as part of pre-processing, a number of filters had to be applied running the risk of erasing peaks or absorptions in the signature that may provide key information when identifying some mineral phases. As it was explained before, to get an image of the whole target area, images from different flights (in the same wavelength domain), had to be mosaicked. During this process, some issues arose, especially in the VNIR domain. It is interesting to note that for different flight surveys but performed on the same day, in apparently the same atmosphere and external conditions, and utilizing the same sensor, the range in the reflectance axis (Y) for the datasets are completely different. For some images varying from 0 to 500 and for others from 0 to 3500. This poses a serious problem when, due to overlapping of flight lines, for a same pixel two completely different values are given. To solve this, the only possible thing that could be done was removing images whose $\mathrm{Y}$-axis ranges were out of line with the general norm. Despite all this was done, it can be clearly appreciated how in the SAM and LSU results (being not so evident for all the endmember abundance maps), this problem still persists. Although this issue should not affect the BR and MWL results, slight signs are suggesting the opposite, so this should be examined in detail. On the other hand, when stacking the datacubes upon the rock waste types SAM has been performed, several issues, once again concerning the reflectance range, had to be faced. VNIR and SWIR HSI had to be normalized together and besides, as there was an overlapping of a few wavelength bands recorded in both ranges, those needed to be removed. LWIR signature had to be stretched as otherwise it would have passed unnoticed in comparison to the VNIR SWIR.

\section{Optimal workflow}

Based on the outcomes of this study, the following workflow recommendations are suggested:

- Addressing the importance of counting with proper training data and validation data to prove our results.

- Emphasizing the benefits of working with the entire wavelength range when it comes to unmixing pixels. As not all minerals have distinguishable features in all parts of the infrared spectrum (VNIR SWIR and LWIR), they may go unnoticed in some ranges, while for others they may be overestimated.

- Being supported and relying on a mineralogical analysis of the rock waste types such an XRD would be extremely recommended. As they seem to perform pretty good in the SAM, knowing the fraction of ore-bearing mineral that each one contains, would allow us to quantify in a very accurate way the value of rock waste

- Having reliable raw data, with proper preprocessing and corrections. In certain approaches, we can assume the errors this lack may cause, such as in MWL and BR, but in others, like the SAM and LSU, they clearly interfere, influencing the results and making them far less trustworthy. 


\section{FINAL DISCUSSION}

- In terms of mineral identification, this study confirms the effectiveness of using HSI for sulfidic rock waste deposits mapping. It has also effectively demonstrated the added value brought to the mineral characterization of rockwastes by incorporating the LWIR spectral range.

- Supervised classifications, especially the Spectral Angle Mapper tool, used as a means of extrapolating mapped rock types to a larger unmapped area have proved satisfactory, but care has to be taken in applying the correct weights to the endmembers to avoid overfitting effects.

- Geological indices generated from simple algorithms such as band ratios and minimum wavelength mapping guided by expert knowledge resulted in the best discrimination of geologic materials in the rock waste deposit. Classification approaches which focus on spectral features that are characteristic within a given mineralization environment are thus considered to be more effective than any naive classification techniques that are based on entire spectra. Geological knowledge of the area and good ground truthing data are of paramount importance. 


\section{REFERENCES}

Bakker, W.H., van Ruitenbeek, F.J.A., van der Werff, H.M.A., Zegers, T.E., Oosthoek, J.H.P., Marsh, S.H., van der Meer, F.D., 2014. Processing OMEGA/Mars express hyperspectral imagery from radiance-at-sensor to surface reflectance. Planet. Space Sci. 90, $1-9$.

Clark, R. N., 1999. Chapter 1: Spectroscopy of Rocks and Minerals, and Principles of Spectroscopy. In: Remote Sensing for the Earth Sciences, Manual of Remote Sensing Volume 3. s.1.:s.n.

Cudahy, T., Jones, M., Thomas, M., Laukamp, C., Caccetta, M., Hewson, R., Rodger, A., Verrall, M., 2008. Next generation mineral mapping: Queensland airborne HyMap and satellite ASTER surveys 2006-2008. Perth Publicly Available Rep. P2007364 152.

Ghamisi, P., Plaza, J., Member, S., Chen, Y., \& Li, J. (2017). Advanced Supervised Classifiers for Hyperspectral Images: A Review. October. https://doi.org/10.1109/MGRS.2016.2616418.

Goetz, A.F.H. (2009) Three decades of hyperspectral remote sensing of the Earth: A personal view. Remote Sens. Environ. 2009, 113, S5-S16.

Gonz, E. (2006). Geology and structure of Rio Tinto Mine Geología y estructura de la Mina de Río Tinto (Faja Pirítica Ibérica, España ). April 2019.

Green, A.A., Berman, M., Switzer, P., Craig, M.D., 1988. A transformation for ordering multispectral data in terms of image quality with implications for noise removal. IEEE Trans. Geosci. Remote Sens. 26, 65-74. https://doi.org/10.1109/36.3001.

Inverno, C., Rosa, C., Matos, J., Carvalho, J., Bellido, F., Ayala, C., Batista, M. J., Rubio, F., Granado, I., Tornos, F., Oliveira, J. T., Rey, C., Araújo, V., Pereira, Z., Represas, P., Solá, A. R., \& Sousa, P. (2015). Introduction and Geological Setting of the Iberian Pyrite Belt. 191208. https://doi.org/10.1007/978-3-319-17428-0.

Julivert, M., Fontboté, J.M., Ribeiro, A., Conde, L., 1974. Mapa tectónico de la Península Ibérica y Baleares. E. 1:1.000.000. Instituto Geológico y Minero de España.

Kruse, F. A., Lefkoff, A. B., \& Dietz, J. B. (1993). Expert system-based mineral mapping in northern deathvalley, California/Nevada, using the Airborne Visible/Infrared Imaging Spectrometer (AVIRIS). Remote Sensing of Environment, 44 (2-3), 309-336. https://doi.org/10.1016/0034-4257(93)90024-R.

L3 Harris Geospatial Solutions. (n.d.). Using ENVI. Retrieved April 16, 2020, from https://www.harrisgeospatial.com/docs/routines-136.html.

Lau, I. C., 2016. Chapter 4 Remote Sensing Background. En: Remote Sensing. s.l.:s.n., pp. 49-109.

Manolakis, Dimitris \&amp; Lockwood, Ronald \&amp; Cooley, Tracy. (2016). Hyperspectral Imaging Remote Sensing. Publisher: Cambridge University Press. 701 pag. ISBN 1107083664 DOI: https://doi.org/10.1017/CBO9781316017876. 
Mellado Sánchez, D. (2006). Geología y estructura de la Mina de Río Tinto (Faja Pirítica Ibérica, España). Geogaceta, 40, 231-234.

Sa, R. (1999). The Iberian type of volcano-sedimentary massive sulphide deposits. 549-570.

Van Ruitenbeek, F.J.A., Bakker, W.H., van der Werff, H.M.A., Zegers, T.E., Oosthoek, J.H.P., Omer, Z.A., Marsh, S.H., van der Meer, F.D., 2014. Mapping the wavelength position of deepest absorption features to explore mineral diversity in hyperspectral images. Planet. Space Sci. 101 (0), 108-117.

Savitzky, A. and M. J. E. Golay (1964). "Smoothing and Differentiation of Data by Simplified Least Squares Procedures”. In: Analytical Chemistry 36.8, pp. 1627-1639. 


\section{APPENDICES}

\section{APPENDIX A1: REPRESENTATIVE TABLES}

Table 1. The XRD results for the test site lithologies.

\begin{tabular}{|c|c|c|c|c|c|c|c|}
\hline & $\begin{array}{l}\text { MK_20 } \\
20072 \\
4 \_001\end{array}$ & $\begin{array}{l}\text { MK_20 } \\
20072 \\
4 \_002\end{array}$ & $\begin{array}{l}\text { MK_20 } \\
20072 \\
4 \_003\end{array}$ & $\begin{array}{l}\text { MK_20 } \\
20072 \\
4 \_004\end{array}$ & $\begin{array}{l}\text { MK_20 } \\
20072 \\
4 \_005\end{array}$ & $\begin{array}{l}\text { MK_20 } \\
20072 \\
4 \_006\end{array}$ & $\begin{array}{l}\text { MK_20 } \\
20072 \\
4 \_007\end{array}$ \\
\hline & $\begin{array}{l}\text { Volcan } \\
\text { ics, } \\
\text { chlori- } \\
\text { tic }\end{array}$ & $\begin{array}{l}\text { Culm } \\
\text { shale }\end{array}$ & $\begin{array}{l}\text { Purple } \\
\text { shale }\end{array}$ & $\begin{array}{l}\text { Argil- } \\
\text { lic } \\
\text { altera- } \\
\text { tion }\end{array}$ & $\begin{array}{l}\text { Stock- } \\
\text { work }\end{array}$ & $\begin{array}{l}\text { Mas- } \\
\text { sive } \\
\text { sulfide }\end{array}$ & $\begin{array}{l}\text { Go- } \\
\text { ssan }\end{array}$ \\
\hline Chlorite & 48.5 & 15.2 & 13.3 & & & & \\
\hline Hematite & & & & & & & 49.7 \\
\hline Muscovite & & 40.4 & 32.0 & 34.1 & & & 8.4 \\
\hline Albite & & 5.3 & & & & & \\
\hline Alunite & & & & & & & 2.8 \\
\hline Barite & & & & & & & 10.9 \\
\hline Beudantite & & & & & & & 3.4 \\
\hline Chalcopyrite & & & & & & 0.4 & \\
\hline Copiapite & & & & & & 3.6 & \\
\hline Goethite & & & & & & & 11.9 \\
\hline Greigite & & & & 0.5 & & & \\
\hline Kaolinite & & & 9.3 & & & & 1.8 \\
\hline Mayenite & & & & & & 0.8 & \\
\hline Pyrite & 3.5 & 0.2 & 0.4 & & 30.2 & 93.4 & 0.3 \\
\hline Quartz & 48.0 & 37.1 & 42.9 & 63.3 & 69.8 & 1.1 & 10.7 \\
\hline Rutile & & 1.8 & 2.2 & 2.2 & & 0.7 & \\
\hline
\end{tabular}

Table 2. Number of pixels from each test site lithology used for the endmember extraction that will constitute the spectral libraries for the VNIR SWIR and LWIR domains.

$$
\text { VNIR (pxI } 0.6 \mathrm{~m}) \quad \text { SWIR (pxI } 1.25 \mathrm{~m}) \quad \text { LWIR (pxI } 1.25 \mathrm{~m})
$$

\begin{tabular}{llll} 
Gossan & 30 & 6 & 9 \\
\hline Massive Sulfide & 30 & 9 & 12 \\
Stockwork & 42 & 8 & 16 \\
\hline Argillic Alteration & 48 & 9 & 12 \\
\hline Purple Shales & 30 & 4 & 12 \\
\hline $\begin{array}{l}\text { Culm Shales } \\
\text { Chloritic }\end{array}$ & 42 & 12 & 16 \\
Volcanics & 154 & & 42
\end{tabular}




\section{APPENDIX A2: TECHNICAL SPECIFICATIONS OF CAMERAS}

HySpex VNIR 1800 Camera Specifications

\begin{tabular}{|l|c|}
\hline Parameter & Specified Value \\
\hline Spectral range & $400-1000 \mathrm{~nm}$ \\
\hline Spatial pixels & 1800 \\
\hline Spectral channels & 186 \\
\hline Spectral sampling & $3.26 \mathrm{~nm}$ \\
\hline FOV* & $17^{\circ}$ \\
\hline Pixel FOV across/along* & $0.16 / 0.32 \mathrm{mrad}$ \\
\hline Bit resolution & $16 \mathrm{bit}$ \\
\hline Noise floor & $2.4 \mathrm{e}-$ \\
\hline Dynamic range & 20000 \\
\hline Peak SNR (at full resolution) & $>255$ \\
\hline Max speed (at full resolution) & $260 \mathrm{fps}$ \\
\hline Power consumption & $30 \mathrm{~W}$ \\
\hline Dimensions (l-w-h) & $39-9.9-15 \mathrm{~cm}$ \\
\hline Weight & $5.0 \mathrm{~kg}$ \\
\hline Camera Interface & CameraLink \\
\hline
\end{tabular}

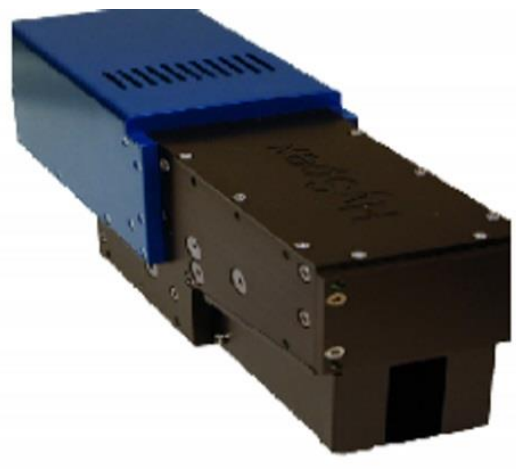


HySpex SWIR 384 Camera Specifications

\begin{tabular}{|l|c|}
\hline Parameter & Specified Value \\
\hline Spectral range & $930-2500 \mathrm{~nm}$ \\
\hline Spatial pixels & 384 \\
\hline Spectral channels & 288 \\
\hline Spectral sampling & $5.45 \mathrm{~nm}$ \\
\hline FOV* & $16^{\circ}$ \\
\hline Pixel FOV across/along* & $0.73 / 0.73 \mathrm{mrad}$ \\
\hline Bit resolution & $16 \mathrm{bit}$ \\
\hline Noise floor & $150 \mathrm{e}-$ \\
\hline Dynamic range & 7500 \\
\hline Peak SNR (at full resolution) & $>1100$ \\
\hline Max speed (at full resolution) & $400 \mathrm{fps}$ \\
\hline Power consumption & $30 \mathrm{~W}$ \\
\hline Dimensions (l-w-h) & $5.7 \mathrm{~kg}$ \\
\hline Weight & CameraLink \\
\hline Camera Interface & \\
\hline
\end{tabular}


HyperCam VLW Camera Specifications

\begin{tabular}{|l|c|}
\hline Parameter & Specified Value \\
\hline Spectral Range & $7.7-11.8$ \\
\hline Spectral Resolution & Up to 0.25 \\
\hline Spectral Resolution & $320 \times 256$ \\
\hline FOV (Field of view) & $6.4 \times 5.1$ \\
\hline Typical nesr & 20 \\
\hline Radiometric Accuracy (K) & $<10$ \\
\hline Data Transfer & Camera Link \\
\hline Power to Consumption & $180 \mathrm{~W}$ \\
\hline Weight & $31 \mathrm{~kg}$ \\
\hline Operating Temperature & -20 to $401 \mathrm{C}$ \\
\hline
\end{tabular}

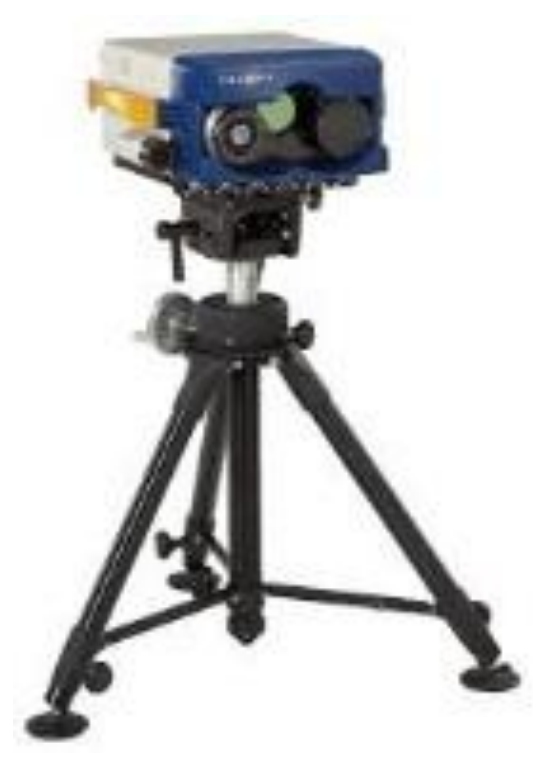


Aisa Fenix Hyperspectral Camera

\begin{tabular}{|c|c|c|}
\hline & VNIR & SWIR \\
\hline \multicolumn{3}{|l|}{ Camera specifications } \\
\hline Spectrograph & \multicolumn{2}{|c|}{$\begin{array}{l}\text { High efficiency transmissive imaging } \\
\text { spectrograph }\end{array}$} \\
\hline Spectral range & $380-970 \mathrm{~nm}$ & $970-2500 \mathrm{~nm}$ \\
\hline Spectral resolution & $3.5 \mathrm{~nm}$ & $12 \mathrm{~nm}$ \\
\hline $\mathrm{F} / \#$ & \multicolumn{2}{|c|}{$\mathrm{F} / 2.4$} \\
\hline Smile / Keystone & \multicolumn{2}{|c|}{$<0.2$ pixels } \\
\hline Polarization sensitivity & \multicolumn{2}{|c|}{ Throughput practically independent of } \\
\hline Signal-to-noise ratio (peak) & $600-1000: 1$ & $1050: 1$ \\
\hline Spatial resolution & \multicolumn{2}{|c|}{384 pixels } \\
\hline Frame rate & Up to $100 \mathrm{~Hz}$ & \\
\hline Integration time & \multicolumn{2}{|c|}{ Adjustable within frame period } \\
\hline FOV & \multicolumn{2}{|c|}{$32.3^{\circ}$} \\
\hline IFOV & \multicolumn{2}{|c|}{$0.084^{\circ}$} \\
\hline Swath width & \multicolumn{2}{|c|}{$0.58 \times$ altitude } \\
\hline Altitude for $1 \mathrm{~m}$ pixel size & \multicolumn{2}{|c|}{$660 \mathrm{~m}$} \\
\hline Electro mechanical shutter & \multicolumn{2}{|l|}{ Yes } \\
\hline Detector & $\begin{array}{l}\text { CMOS Stirling cooled } \\
\text { MCT }\end{array}$ & $\begin{array}{c}\text { Stirling cooled } \\
\text { MCT }\end{array}$ \\
\hline Spectral binning options & $2 x \quad 4 x$ & - \\
\hline Number of spectral bands & $\begin{array}{lll}348 & 174 & 87\end{array}$ & 274 \\
\hline Spectral sampling / band & $1.7 / 3.4$ / $6.8 \mathrm{~nm}$ & $5.7 \mathrm{~nm}$ \\
\hline Data interface & CameraLink 12-bit & $\underset{1-:}{\text { CameraLink 16- }}$ \\
\hline Typical power consumption & \multicolumn{2}{|c|}{$150 \mathrm{~W}$} \\
\hline $\begin{array}{ll}\text { Maximum } \quad \text { power } \\
\end{array}$ & \multicolumn{2}{|c|}{$500 \mathrm{~W}$} \\
\hline Environmental & \\
\hline Storage temperature & \multicolumn{2}{|c|}{$-20 \ldots+50 \stackrel{\circ}{C}$} \\
\hline Operating temperature & \multicolumn{2}{|c|}{$+5 \ldots+40^{\circ} \mathrm{C}$, non-condensing } \\
\hline
\end{tabular}




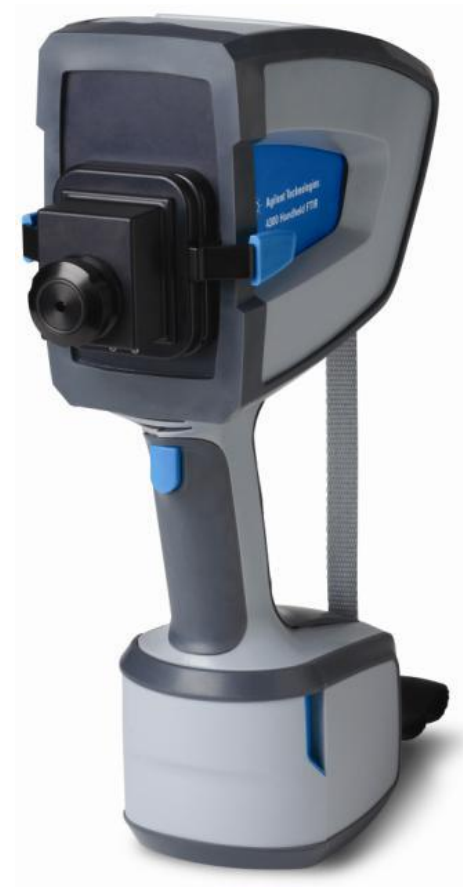

Agilent $\mathbf{4 3 0 0}$ Handheld FTIR

\begin{tabular}{|l|c|}
\hline Parameter & Specified Value \\
\hline Size & $10 \times 19 \times 35 \mathrm{~cm}$ \\
\hline Weight & $1.88 \mathrm{~kg}$ \\
\hline Power & $\begin{array}{c}\text { Two Internal batteries (3 h), 100/120/240 V } \\
\text { AC, } 50 / 60 \mathrm{~Hz}\end{array}$ \\
\hline Spectral range DTGS & $\begin{array}{c}4500-650 \mathrm{~cm}-1 \\
\text { Resolution }\end{array}$ \\
\hline Controller & $\begin{array}{c}4-16 \mathrm{~cm}-1 \\
\text { Integrated CPU with Microsoft Windows CE } \\
6.00 \text { Edition }\end{array}$ \\
\hline Software & $\begin{array}{c}\text { Can be operated by Agilent MicroLab PC or } \\
\text { Mobile software }\end{array}$ \\
\hline Warmup time & 10 min \\
\hline Response time & 2 min \\
\hline Operating temperature & $0-50{ }^{\circ} \mathrm{C}$ \\
\hline
\end{tabular}




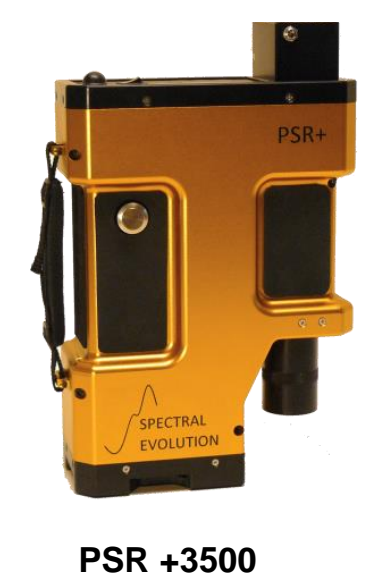

\begin{tabular}{|c|c|}
\hline Parameter & Specified Value \\
\hline Spectral range & $350-2500 n m$ \\
\hline $\begin{array}{l}\text { Spectral Resolution- FWHM } \\
\text { (Full Width at Half Maximum) }\end{array}$ & 2,8 nm @700 nm; 8 nm @1500; 6 nm @2100 \\
\hline Si Detector & 512 elements Si photodiode array $(350-1000 \mathrm{~nm})$ \\
\hline InGas Detectors (cooled) & 512 elements Si photodiode array (350-1000nm) \\
\hline FOV* & $17^{\circ}$ \\
\hline Fiber Mount Otions & $0.16 / 0.32 \mathrm{mrad}$ \\
\hline Noise Equivalence Radiance & 16 bit \\
\hline Max Radiance & $2.4 \mathrm{e}-$ \\
\hline Minimum Scan Speed & 20000 \\
\hline Wavelength Reproducibility & $>255$ \\
\hline Wavelength Accuracy & 0,5 band width \\
\hline Communications Interface & USB or Class I Bluetooth- laptop or PDA compatible \\
\hline Size & $8,5 \times 11,5 \times 3,25$ \\
\hline Tripod Mounting & 2 each $1 / 4-20$ mounting holes provided \\
\hline Weight & $3,5 \mathrm{~kg}$ \\
\hline Batteries & Lithium ion; 7,4 V; $7200 \mathrm{mAh} ; 400 \mathrm{~g} /$ battery \\
\hline Battery Operation & Removable battery; tipically up to 4 hour \\
\hline On Board Memory & Storage of 1000 spectra \\
\hline
\end{tabular}




\section{APPENDIX A3: LINEAR SPECTRAL UNMIXING RESULTS}
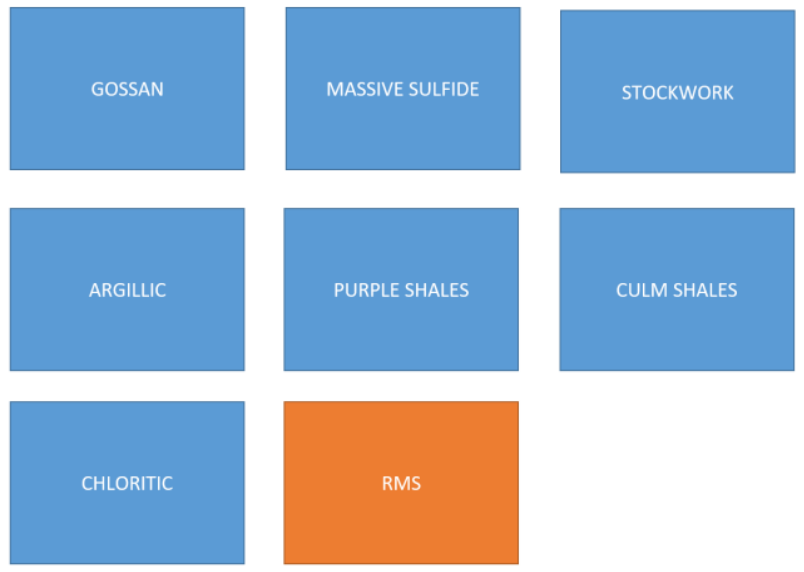

Fig. 1. Image layout scheme.
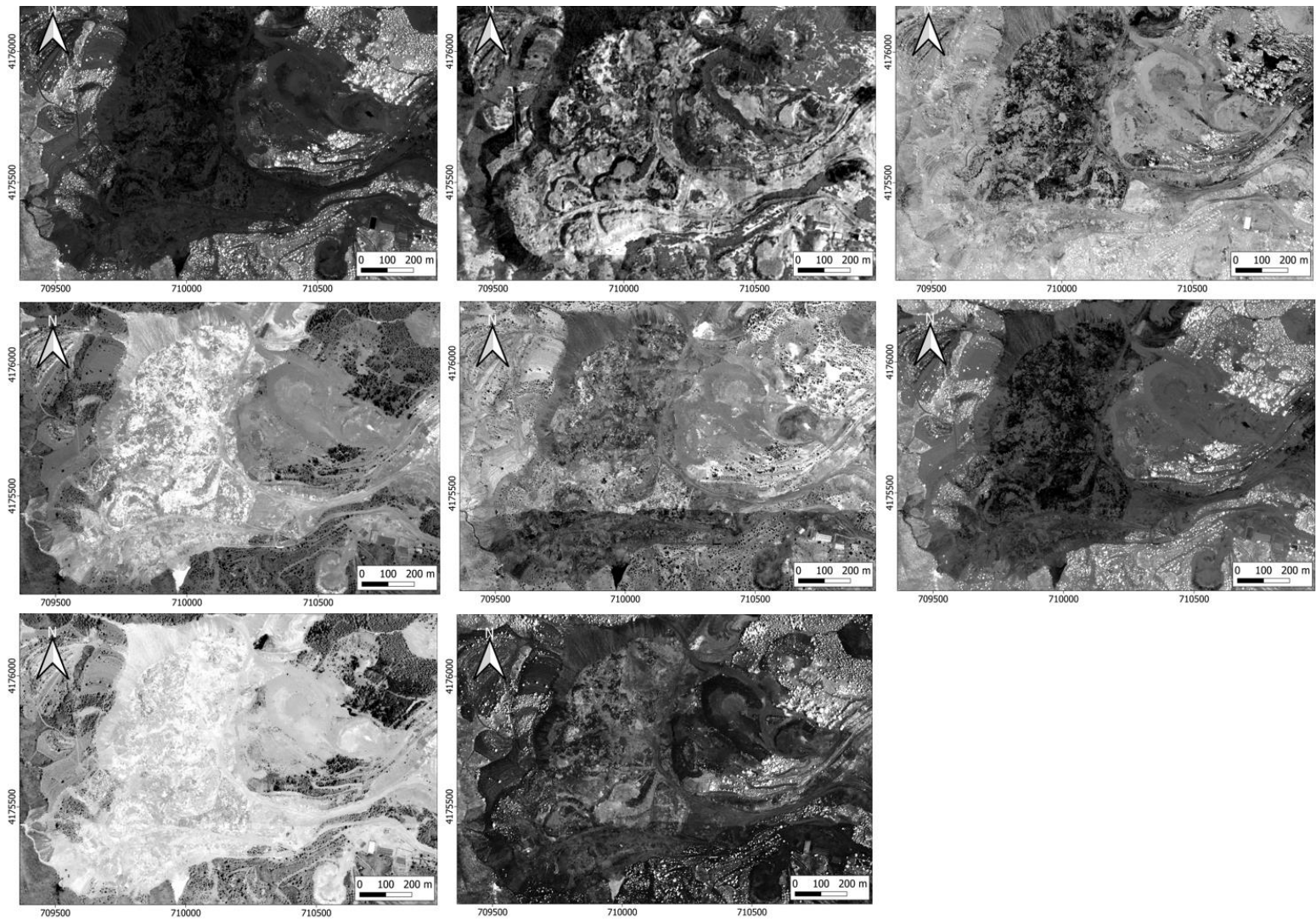

Fig. 2. VNIR Linear spectral unmixing. Abundance maps for each endmember and RMS error image 

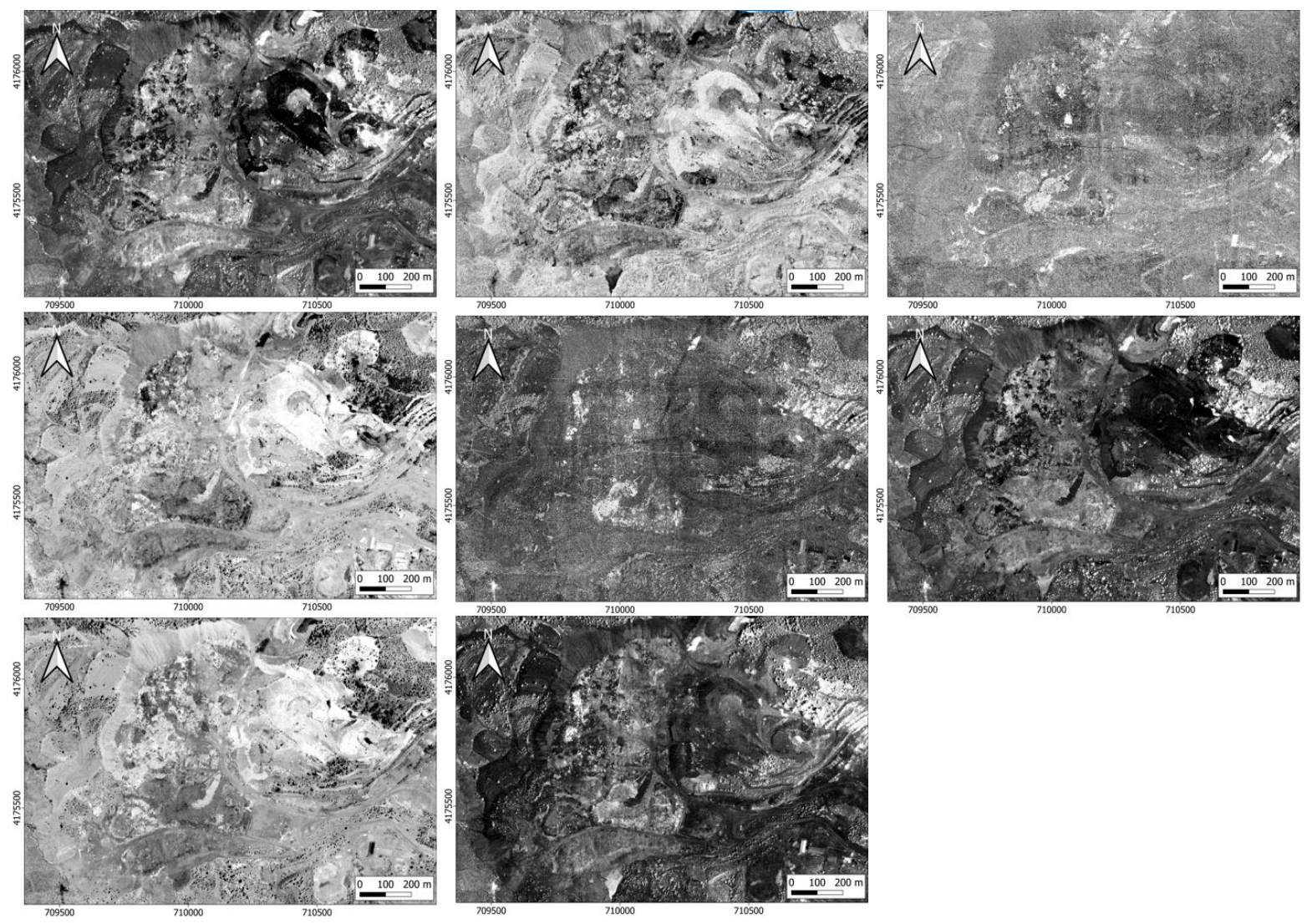

Fig. 3. SWIR Linear spectral unmixing. Abundance maps for each endmember and RMS error image
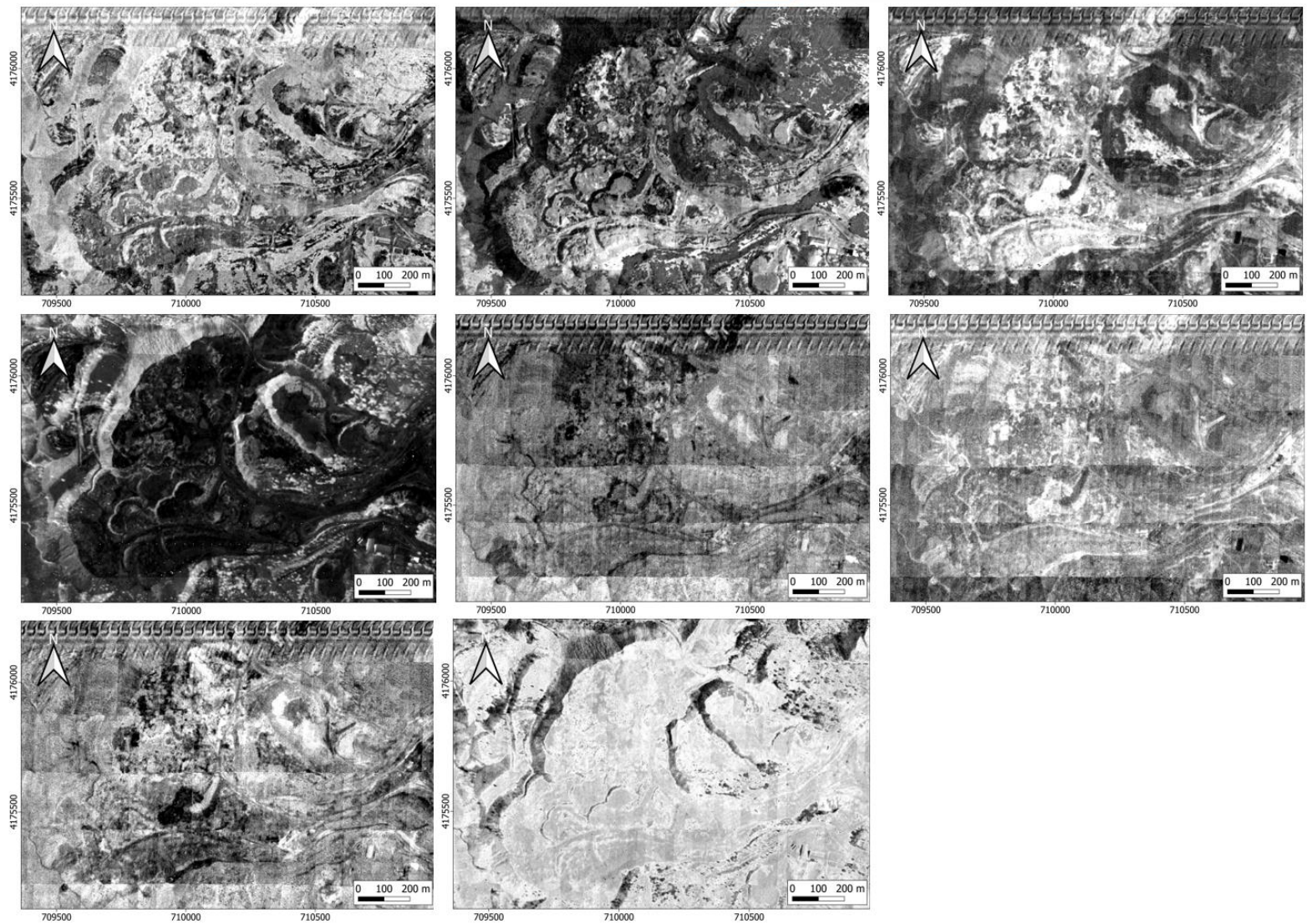

Fig. 4. LWIR Linear spectral unmixing. Abundance maps for each endmember and RMS error image 


\section{APPENDIX A4: ROCK WASTE TYPES SPECTRAL LIBRARY}

End-member spectral library corresponding to the rock waste types classification. These spectra are the result of the arithmetic mean of the collected pixels from the stack datacube (VNIR, SWIR and LWIR).
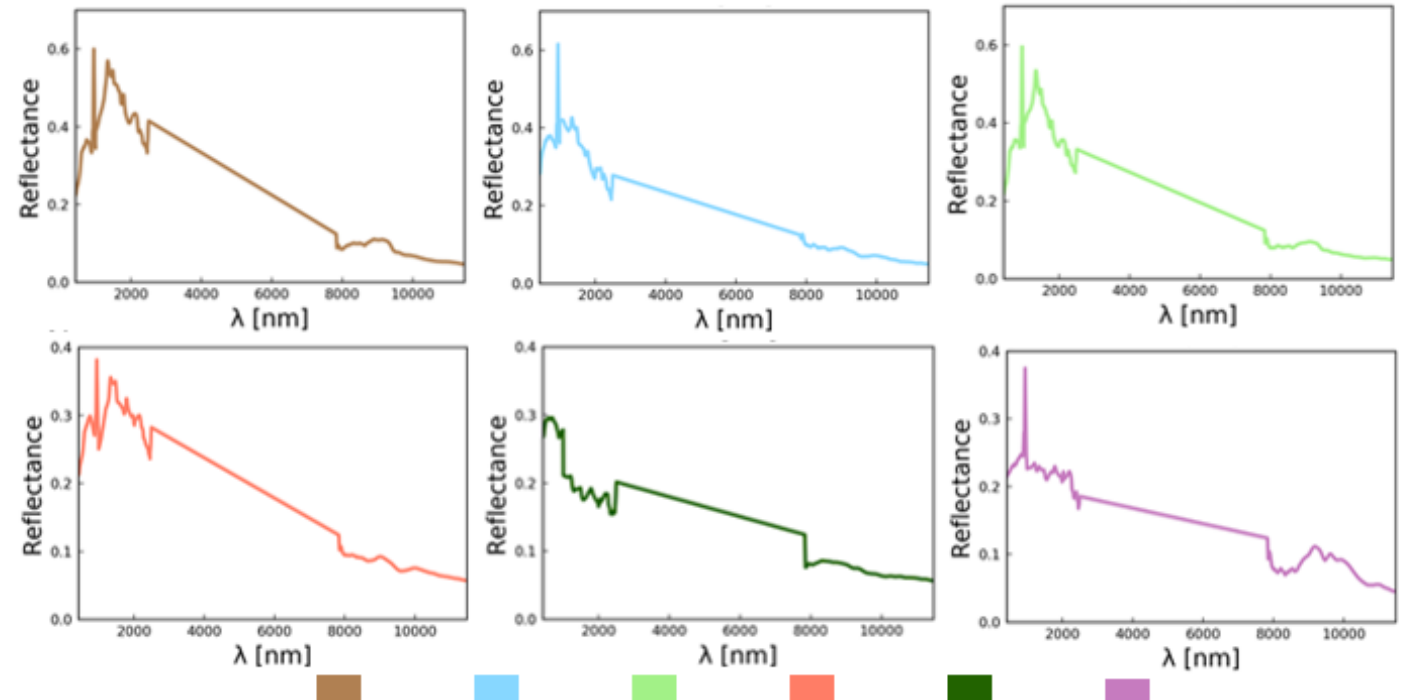

STK A-STK MIX G $\quad$ MS SLATES

Fig. 27. Rockwaste types spectral library 